\title{
Morphology of Stephanella hina (Bryozoa, Phylactolaemata): common phylactolaemate and unexpected, unique characters
}

\author{
Thomas F. Schwaha ${ }^{1 *}$ and Masato Hirose ${ }^{2}$ (1)
}

\begin{abstract}
Stephanella hina is a little studied freshwater bryozoan belonging to Phylactolaemata. It is currently the only representative of the family Stephanellidae, which in most reconstructions is early branching, sometimes even sister group to the remaining phylactolaemate families. The morphological and histological details of this species are entirely unknown. Consequently, the main aim of this study was to conduct a detailed morphological analysis of $S$. hina using histological serial sections, 3D reconstruction, immunocytochemical staining and confocal laser scanning microscopy techniques. The general morphology is reminiscent of other phylactolaemates; however, there are several, probably apomorphic, details characteristic of S. hina. The most evident difference lies in the lophophoral base, where the ganglionic horns/extensions do not follow the traverse of the lophophoral arms but bend medially inwards towards the mouth opening. Likewise, the paired forked canal does not fuse medially in the lophophoral concavity as found in all other phylactolaemates. Additional smaller differences are also found in the neuromuscular system: the rooting of the tentacle muscle is less complex than in other phylactolaemates, the funiculus lacks longitudinal muscles, the caecum has smooth muscle fibres, latero-abfrontal tentacle nerves are not detected and the medio-frontal nerves mostly emerge directly from the circum-oral nerve ring. In the apertural area, several neurite bundles extend into the vestibular wall and probably innervate neurosecretory cells surrounding the orifice. These morphological characteristics support the distinct placement of this species in a separate family. Whether these characteristics are apomorphic or possibly shared with other phylactolaemates will require the study of the early branching Lophopodidae, which remains one of the least studied taxa to date.
\end{abstract}

Keywords: Stephanellidae, Bryozoan evolution, Epistome, Myoanatomy

\section{Introduction}

Phylactolaemate bryozoans are, from an evolutionary perspective, very interesting, as they comprise the sister group to the two remaining taxa, Stenolaemata and Gymnolaemata $[1,2]$. They are a small group of $\sim 80$ recent species, and due to lack of calcification and hard

\footnotetext{
* Correspondence: thomas.schwaha@univie.ac.at

'Department of Evolutionary Biology, University of Vienna, Althanstraße 14, 1090 Vienna, Austria

Full list of author information is available at the end of the article
}

tissues, they rarely fossilize. Several characteristics are typical of this taxon: a horseshoe-shaped lophophore (suspension-feeding tentacle crown), body-wall musculature and an epistome-a flap-like ciliated bulge protruding over the mouth opening, probably involved in feeding [3, 4]. Morphological analyses usually unite bryozoans with brachiopods and phoronids as "lophophorates" due to similarities in their general body plan, including an epistome-like structure in all groups and, at least in some representatives of the other two taxa, a

(c) The Author(s). 2020 Open Access This article is licensed under a Creative Commons Attribution 4.0 International License, which permits use, sharing, adaptation, distribution and reproduction in any medium or format, as long as you give appropriate credit to the original author(s) and the source, provide a link to the Creative Commons licence, and indicate if changes were made. The images or other third party material in this article are included in the article's Creative Commons licence, unless indicated otherwise in a credit line to the material. If material is not included in the article's Creative Commons licence and your intended use is not permitted by statutory regulation or exceeds the permitted use, you will need to obtain permission directly from the copyright holder. To view a copy of this licence, visit http://creativecommons.org/licenses/by/4.0/ The Creative Commons Public Domain Dedication waiver (http://creativecommons.org/publicdomain/zero/1.0/) applies to the data made available in this article, unless otherwise stated in a credit line to the data. 
horseshoe-shaped lophophore (e.g., [5, 6]). This concept initially gained almost no support through molecular studies but has recently been supported in more recent phylogenies (e.g., [7]). Nonetheless, the phylactolaemate body plan is, from a morphological perspective, the most similar to other lophophorate taxa. Hence, their study is not only important for gaining more insight into the ground pattern of bryozoans and their character evolution but also for making possible phylogenetic inferences on a broad scale.

Six to seven families are currently distinguished among Phylactolaemata, with the large bulk of species belonging to the Plumatellidae, and all other families consisting of one to five species. Several older studies agreed that the genus Stephanella, the sole genus of the Stephanellidae, represents an early branch within phylactolaemate diversification, a notion also supported by more recent molecular analyses [8,9]. Most studies concerning this genus dealt with its taxonomy and distribution [10, 11]. In addition to the original description from Oka [12], one study has applied more sophisticated methods to investigate the morphology of this species [13]. Only recently, Stephanella hina was documented and analysed properly for the first time [14]. Several peculiarities, such as the very thin connections between individual zooids within a colony and their tube-like cystids, are unique to phylactolaemates. In addition, the body wall secretes a mostly unconnected tube rather than a cuticular ectocyst, as found in other bryozoans, which is also unique for this species [14]. In the past decade, fluorescence staining methods and confocal laser scanning microscopy have been increasingly applied to the study of adult bryozoans [e.g., 15-21]. Since S. hina remains an important representative, the aim of this work was to use histological as well as fluorescence techniques to investigate this neglected species in more detail to compare it with other phylactolaemates.

\section{Material \& Methods}

Samples were collected from 2014 to 2016 in Tsukuba or a nearby pond as previously described by Schwaha et al. [14]. Samples were either fixed for sectioning in $2-2.5 \%$ glutaraldehyde in $0.01 \mathrm{M}$ sodium cacodylate buffer ( $\mathrm{pH}$ 7.4) for approximately $2 \mathrm{~h}$ or for fluorescence staining in $4 \%$ paraformaldehyde in 0.1 $\mathrm{M}$ phosphate buffer ( $\mathrm{pH}$ 7.4) for 1 hour. Samples were afterwards rinsed several times in the corresponding buffer and further processed or stored in buffer containing $\sim 0.1 \% \mathrm{NaN} 3$ until further preparation. Further processing for sectioning and fluorescence staining was conducted as previously described (see, e.g., $[15,16])$.

\section{Results}

\section{General morphology}

The zooids of a colony have an attached basal part and an attached vertical tube that contains the polypide extending from it. The attached basal part shows elongated extensions that interconnect zooids in a colony (see [14] and Fig. 1a). The cystid wall consists of the cellular endocyst and extracellular ectocyst (Fig. 2). At the distal tip of the cystid lies the orifice (Fig. 3d, e), where polypides protrude from or retract into. At the margin of the cystid, the vestibular wall folds proximally (Fig. 3). It is short but always of prominent thickness (Figs. 1; 3). The cells at its distal border always show a large vacuole of homogenous content (Fig. 3), which at least partially also stain for anti-acetylated tubulin (Fig. 4b, e). Proximally, the vestibular wall terminates at the diaphragm (Fig. 3d), which characteristically possesses a distinct sphincter muscle [17]. The sphincter is not clearly distinguishable from the remaining circular muscles of the vestibular wall in Stephanella hina. From the diaphragm, the thin introvertable tentacle sheath extends towards the lophophoral base (Fig. 1b). The horseshoe-shaped lophophore carries approximately 32-34 ciliated tentacles and surrounds the central mouth opening. From the anal side, a ciliated flap, the epistome, protrudes slightly above the mouth opening (Fig. 1b). The mouth opening enters the $\mathrm{u}$-shaped gut, which terminates via the anus in the tentacle sheath.

\section{Cystid structure}

The body wall is bi-layered and consists of an outer epidermis and an inner peritoneal layer. For the most part, the endocyst is thin, but locally thicker areas of the epidermal layer are present. These areas are glandular and are frequently encountered in the epidermal layer (Fig. $2 \mathrm{e}-\mathrm{i})$, although distinct cellular inclusions can also sometimes be found in the peritoneum (Fig. 2b). Overall, both layers of the endocyst can have increased thickness, and variants with one layer being thicker than the other or both being of equal thickness have been encountered (Fig. 2). Distinct reasons for this variation could not be found but might be linked with the ectocyst thickness (see below). Only at the basal part, where the zooid is directly attached to the substrate and from where the prominent retractor muscles originate, can a prominent endocyst always be ascertained (Fig. 2h, i). Glandular cells in the endocyst appear mostly vacuolar with a spacious cavity of homogenous or heterogeneous content (Fig. 2e-g, i). In addition, a second type of gland cell with numerous, smaller translucent cavitations or vesicles occurs in the epidermis.

External to the epidermis lies the ectocyst, which has only little contact with the epidermis and is secreted as multilayered tubes (see also Schwaha et al. 2016). During 

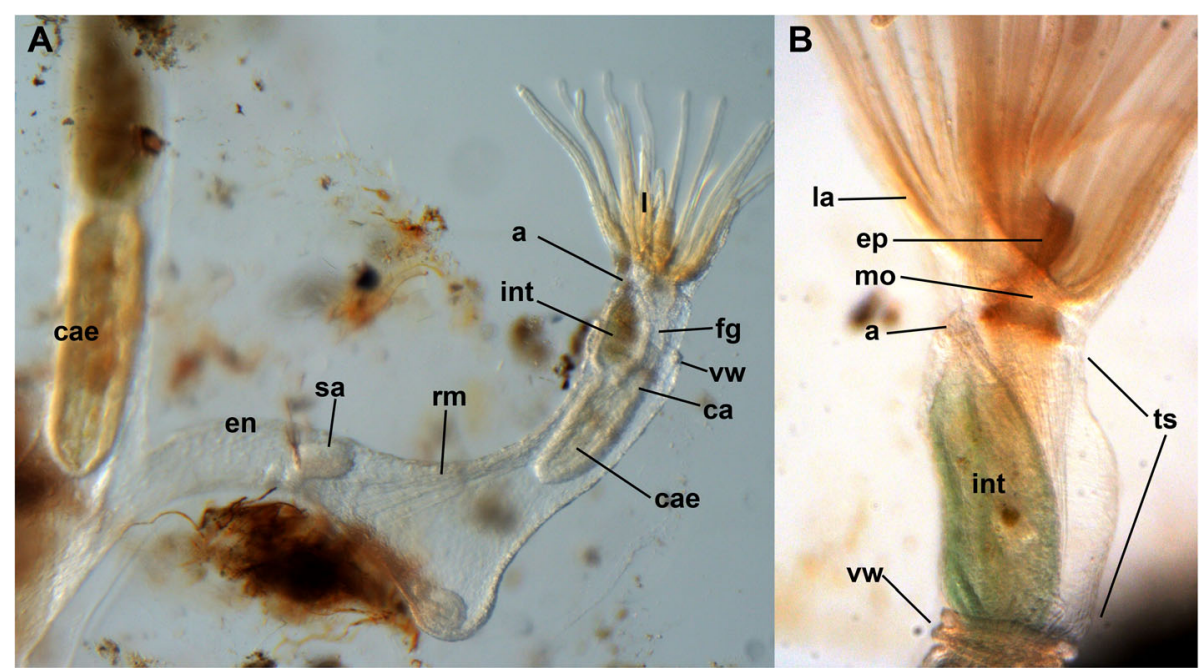

Fig. 1 General overview of Stephanella hina. Live specimens. a Lateral view of two zooids on the budding tip, with a younger zooid on the right and an older zooid on the left. b Detail of a single zooid including several morphological characteristics. Abbreviations: a - anus, ca - cardia, cae caecum, en - endocyst, ep - epistome, fg - foregut, int - intestine, I - lophophore, la - lophophoral arm, mo - mouth opening, rm. - retractor muscle, sa - statoblast anlage, ts - tentacle sheath, vw - vestibular wall

histological preparation, it shrinks extensively and covers the epidermis more closely. The ectocyst is a translucent, sticky hull secreted by the endocyst. It consists of numerous concentric layers that on sections are discernible as concentric rings containing densely stained, minute particles. The outer- and innermost layers often stain more intensely and conspicuously than the middle layers (Fig. 2a, c, d). Close to the epidermis, these layers appear denser, whereas the outer margin shows larger gaps between each layer (Fig. 2a, c).

\section{Lophophore}

The tentacle crown, or lophophore, of Stephanella hina is horseshoe shaped and has rather short lophophoral arms (Figs. 1; 5). On the oral side of the lophophore, there are eight tentacles supplied by the ring canal situated at the lophophoral base and showing lateral open connections to the remaining body cavity. The lateral tentacles and most on the lophophoral arms are largely confluent with the remaining coelomic cavity. Only the tentacles on the anal side above the epistome show two additional canalized extensions (Fig. 5). The openings of these canals are wide and located at the lophophoral base, approximately in the area of the cerebral ganglion. The canals show dense ciliation of the inner peritoneal lining (Fig. 6d), and each supply two canals that protrude above the epistome coelom medially but do not fuse in their median plane (Fig. 5). The epistome coelom is an extension from the remaining body cavity between the oral and anal gut shanks reaching above the cerebral ganglion, which is located on the anal side of the pharynx, and protrudes medially in the direction of the mouth opening.

The epidermal lining of the epistome shows great variation in its histological differentiation. It always consists of highly prismatic elongated cells stretching from the lophophoral base towards the mouth opening (Fig. 7). The cells of the epistome epithelium can be inconspicuous (Fig. 7g) or only show numerous (partially osmiophilic) secretory droplets or vesicles (Fig. 7f), but in the majority of observations, it shows active secretion of globular vesicles in a holocrine manner (Fig. 7a-c, e, g). Such secretions are encountered in various stages from bulges from the epistome epidermis (Fig. 7e) to elongated, stalked cells with only little contact with the remaining epithelium (Fig. $7 \mathrm{~b}$ ) to separate globules pinched off from the epithelium or within the area of the mouth opening (Fig. 7a-c, g). A similar condition is present at the beginning of the digestive tract, in the epithelium proximal to the epistome (Fig. 7d). These secretory activities are reflected by the reddish-brownish coloration of these areas in live animals (Fig. 1).

The tentacles are proximally united at the lophophoral base. In cross-section, the tentacles typically show a frontal side facing the mouth opening and an abfrontal side facing the opposite direction. Frontally, the epidermal lining is thickest and gradually diminishes in size from the lateral towards the abfrontal side, where the epithelium is only thin (Fig. 8c-h). Frontal and lateral cilia are readily distinguishable in the tentacles (Fig. 8h), whereas distinct latero-frontal cilia are not detected at this level of resolution. Medially, a considerable extracellular matrix separates the outer epidermal layer from the 


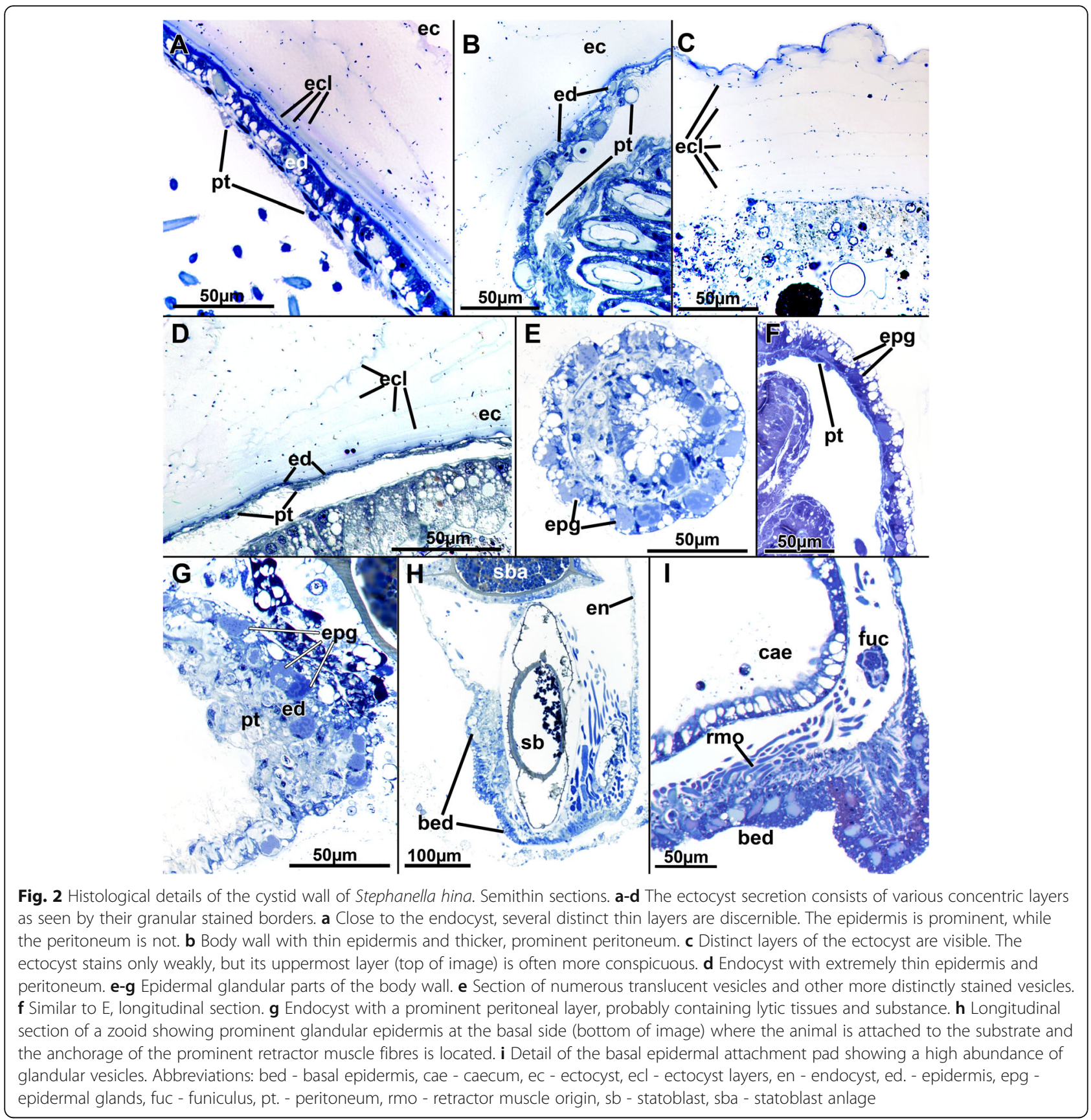

inner peritoneal lining of each tentacle coelom (Fig. 8). The latter is always thin and bordered on each lateral side by a pair of subperitoneal cells. On sections, these appear homogenously filled (Fig. 8c, d, g). In retracted polypides, the subperitoneal cells often locally bulge medially and suppress the tentacle coelom to the frontal and abfrontal sides (Fig. 8c, d). These cells appear to accompany each tentacle over its entire length, and the nuclei of these cells are only encountered directly at the lophophoral base, shortly before the tentacles individualize from the remaining lophophoral base (Fig. 8a, b). At the tip of each tentacle, a distinct ciliary bundle is present. It seems to be restricted to a few cells in the epidermal tip (Fig. 9).

A distinct intertentacular membrane interconnects each tentacle on their abfrontal sides, close to the lophophoral base. It is merely a thin epidermal duplicature that either is directly integrated into the epithelium of the abfrontal side of each tentacle (Fig. 8f) or has a thin pedicle extending from the membrane to the abfrontal side of tentacles (Fig. 8e). 


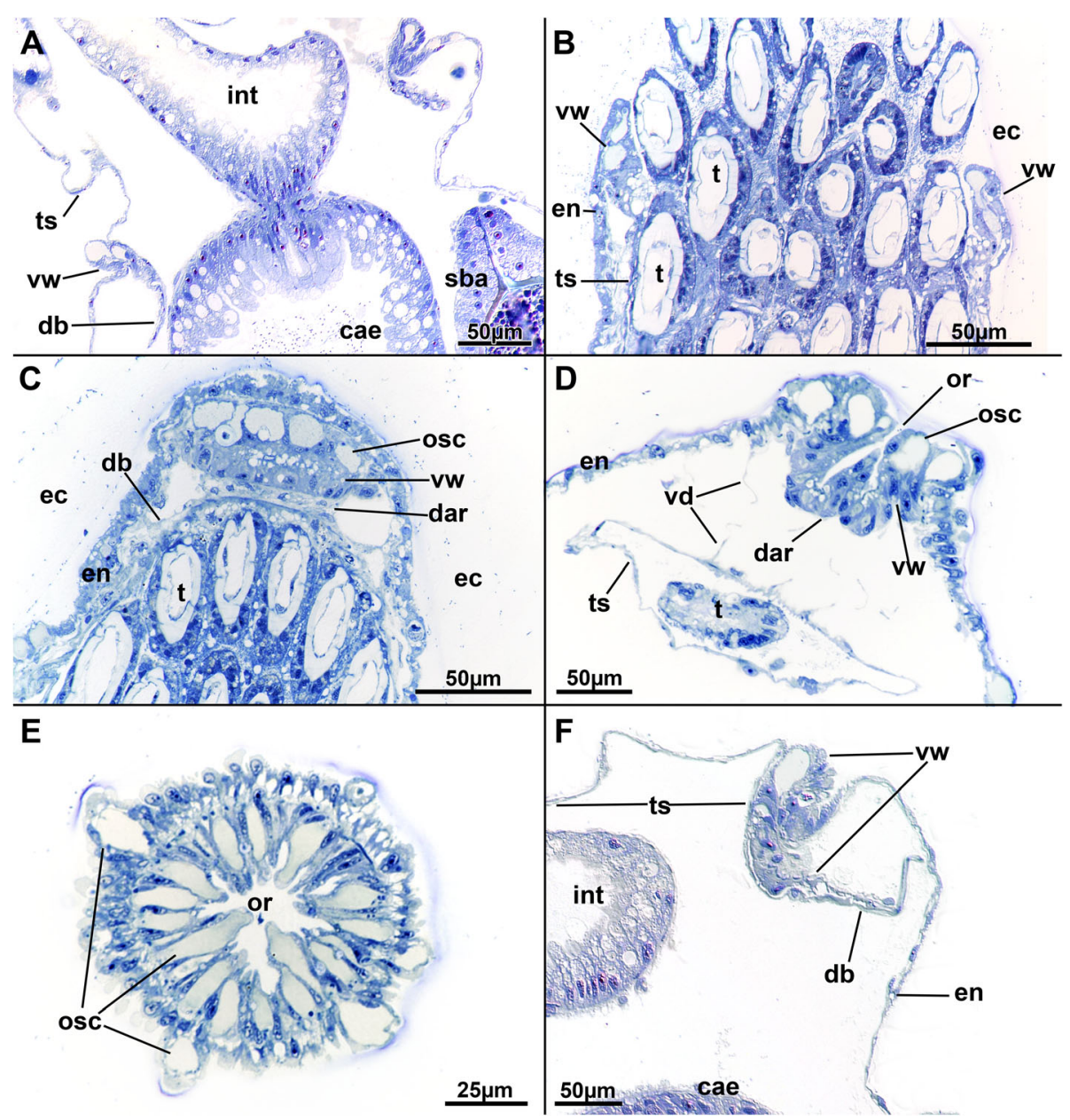

Fig. 3 Histological details of the vestibular area of Stephanella hina. Semithin sections. a Longitudinal section of an extended polypide. b Oblique section of a slightly extended specimen showing the apertural area. $\mathbf{c}$ Longitudinal section through the vestibular wall of a zooid with retracted polypide showing the dense glandular/sensory (?) orificial cells. d Median longitudinal section of the apertural area of a zooid with retracted polypide. e Cross-section of the folded vestibular wall with contracted vestibular wall musculature. $\mathbf{f}$ Close-up of the vestibular wall of a protruded specimen (compare to A). Abbreviations: cae - caecum, dar - diaphragmatic area, db - duplicature band, ec - ectocyst, en - endocyst, int - intestine, or - orifice, osc - orificial (sensory?) cells, sba - statoblast anlage, t - tentacle, ts - tentacle sheath, vd - vestibular dilatators, vw vestibular wall

\section{Digestive tract and funiculus}

The digestive tract of Stephanella hina consists of three distinct regions: fore-, mid- and hindgut (Fig. 1). At the lophophoral base, the mouth opening continues into the pharynx followed by the esophagus, which both represent the foregut. The area of the mouth opening has highly prismatic cells with distinct ciliation (Fig. 10a, b, d) that often forms a flat ciliated disc (in protruded polypides) (Figs. 10a; 11b). Proximal to the ciliated area, the pharynx is characterized by a prominently vacuolated epithelium, which shows some variation among analysed specimens (Fig. 10a-e). Apically towards the gut lumen, several smaller vesicular inclusions can be found to various extents (Fig. 10b, d, e). The remaining epithelium is filled with spacious vacuoles (Fig. 10). The nuclei of the pharyngeal epithelium are located in the middle of the baso-apical axis and appear pycnotic (Fig. 10a-e). The adjacent esophageal area shows similar cytological details to the upper pharynx but is much thinner in its extent and has basally located nuclei in the epithelium (Fig. 10f). The midgut consists of a tubular cardia separated from the esophagus by the cardiac valve (Figs. 10f; 11a, b; 12a, b). Cardiac epithelial cells show apical extensions that appear to be secretions released into the gut lumen (Fig. 12b). Proximally, the cardia enters the voluminous caecum, which in S. hina shows a high disparity regarding its histological structure. Its cells show various degrees of cellular inclusions (Fig. 12c-e). Some areas of the caecum show distinct, intensely stained areas in its lining (Fig. 12e). The hindgut or intestine is the last distinct part of the gut and continues on the anal side of the caecum. It forms a small ellipsoid chamber that 

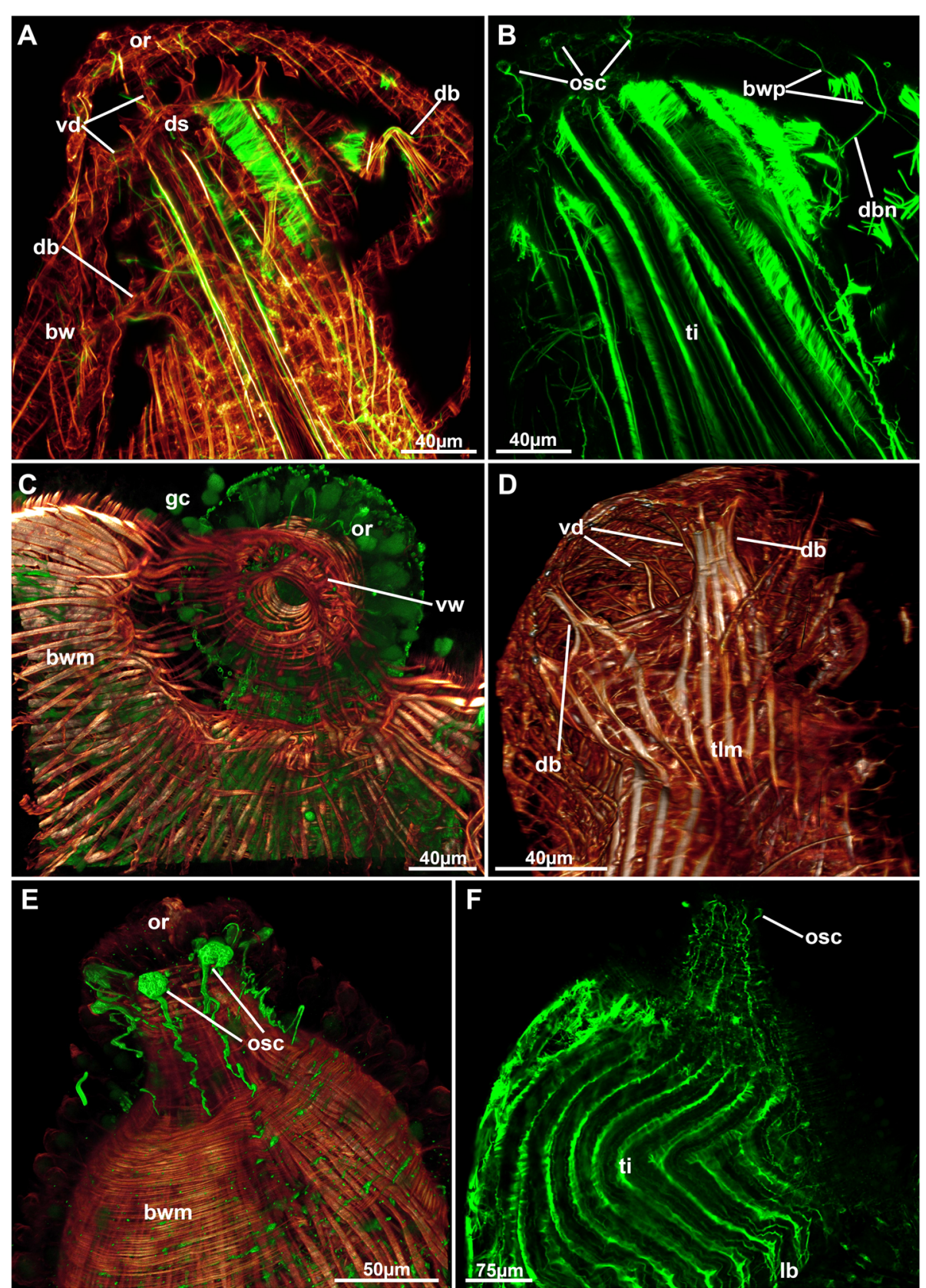

Fig. 4 Neuro-muscular system of the apertural area of Stephanella hina. Confocal laser scanning microscopy stacks based on acetylated alpha-tubulin labelling. Volume renderings, projections or optical slices. Acetylated alpha-tubulin in green LUT, f-actin in glow LUT. a Projection of a zooid with a retracted polypide showing duplicature bands and vestibular dilatators. $\mathbf{b}$ Thin neurite bundles traversing the duplicature bands and extending towards the conspicuous orificial cells. c Volume rendering of the orificial area of a zooid with a retracted polypide showing a closed vestibular area surrounded by stained gland cells. $\mathbf{d}$ Lateral view of a retracted zooid showing duplicature bands and vestibular dilatators. $\mathbf{e}$ Details of specific orificial cells. $\mathbf{f}$ Thin neurite bundles extending along the distal body wall towards the orificial cells. Abbreviations: bw - body wall, bwm - body wall musculature, bwp - body wall nervous plexus, db - duplicature band, dbn - duplicature band neurites, ds - diaphragmatic sphincter, gc - gland cell, or - orifice, osc - orificial (sensory?) cells, ti - tentacle innervation, tIm - tentacle sheath longitudinal muscles, vd - vestibular dilatators, $\mathrm{vw}$ - vestibular wall

enters the tentacle sheath with the anus approximately at the height of the lophophoral base and mouth opening (Figs. 1; 12g). The cells of the intestine are not as prominent as the midgut and show only small vesicular inclusions (Fig. 12f).
At the proximal end of the caecum, a thin peritoneal cord, the funiculus, extends as an elongated tube towards the basal body wall (Fig. 13c). Its lining cells are mostly thin, and in retracted polypides, the funiculus forms several loops within the body cavity (Fig. 13). 

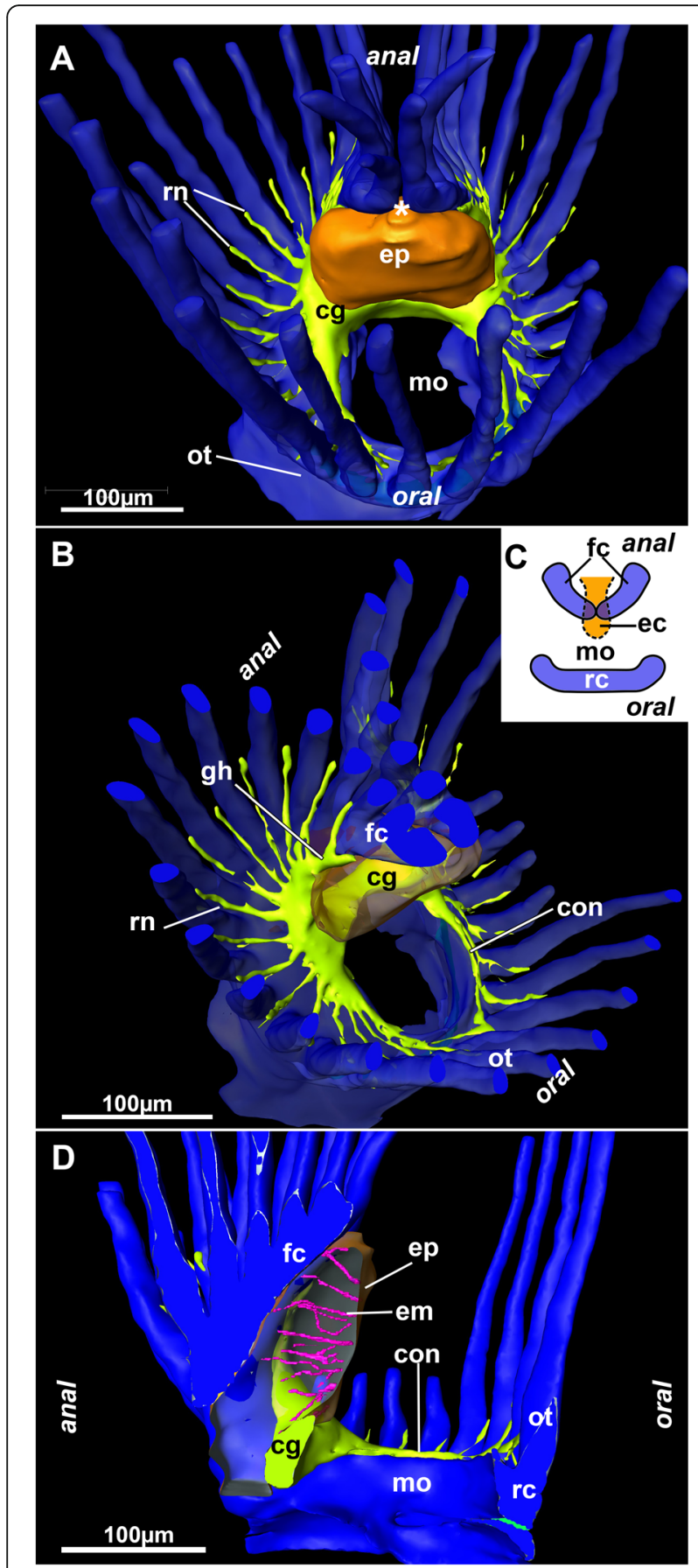

Fig. 5 3D reconstruction of serial semithin sections of the lophophoral base of Stephanella hina. Nervous system in yellow, epistome in orange and coelomic cavity in blue. a Oral view of the lophophoral base showing the epistome above the cerebral ganglion. Note that the inner lophophoral arc (forked canals) is not fused (asterisk). $\mathbf{b}$ Oblique view of the lophophoral base with the epistome displayed transparently. c Schematic drawing of the three coelomic canals, the forked canal and the epistome canal on the anal side and the ring canal on the oral side. $\mathbf{d}$ Lateral view of the epistome including the muscles traversing its cavity. Abbreviations: cg - cerebral ganglion, con - circumoral nerve ring, ec - epistomial coelom, em - epistome muscles, ep - epistome, fc - forked canal, gh - ganglionic horn, mo - mouth opening, ot - oral tentacles, rc ring canal, rn - radial nerve

Statoblasts are formed in the funiculus and in several specimens can be found at several locations. The funicular epithelium forms a regular, thin wrapping around each statoblast anlage (Fig. 13a, b).

\section{Muscular system}

Six principal sets of muscles can be distinguished in bryozoans $[17,18]$ that in Stephanella hina consist of 1) body wall muscles in a regular, orthogonal grid of longitudinal and circular muscles (Figs. 4c, e; 13b; 14a, e). The inner longitudinal muscles are, in most parts of the body wall, thicker and more prominent than the circular ones. 2) Apertural muscles consisting of radially arranged peritoneal duplicature bands supplied with longitudinal muscles and separate vestibular dilatators. Both originate from the tentacle sheath close to the vestibular wall and extend towards the lateral body wall. The duplicature bands originate more proximally, directly from the muscles of the tentacle sheath, and the dilatators, more distally from the area of the diaphragmatic sphincter (Figs. 3a, c, d, f; 4a, d). The diaphragmatic sphincter separating the tentacle sheath from the vestibular wall is not distinguishable from the remaining circular vestibular wall musculature. 3) Tentacle sheath muscles that predominantly show thick longitudinal but also thinner circular fibres (Fig. 4 D; 14a, c). The arrangement is reminiscent of that of the body wall, with prominent longitudinal fibres and more delicate circular fibres. 4) Digestive tract muscles present only in a circular arrangement in the lining of the digestive tract (Fig. 11). These are densely arranged into thick muscle bundles over the entire range of the gut. The fibres of the foregut (pharynx and esophagus) and first part of the midgut, the cardia, have striated muscle fibres (although sometimes the striation is not readily evident). The remaining gut shows smooth muscle fibres. Funicular musculature was not detected. 5) Lophophoral muscles. Each tentacle has two longitudinal muscle bands, one on the frontal (i.e., facing the mouth opening) side and one on the abfrontal (i.e., facing the outer edge of the lophophore) side 

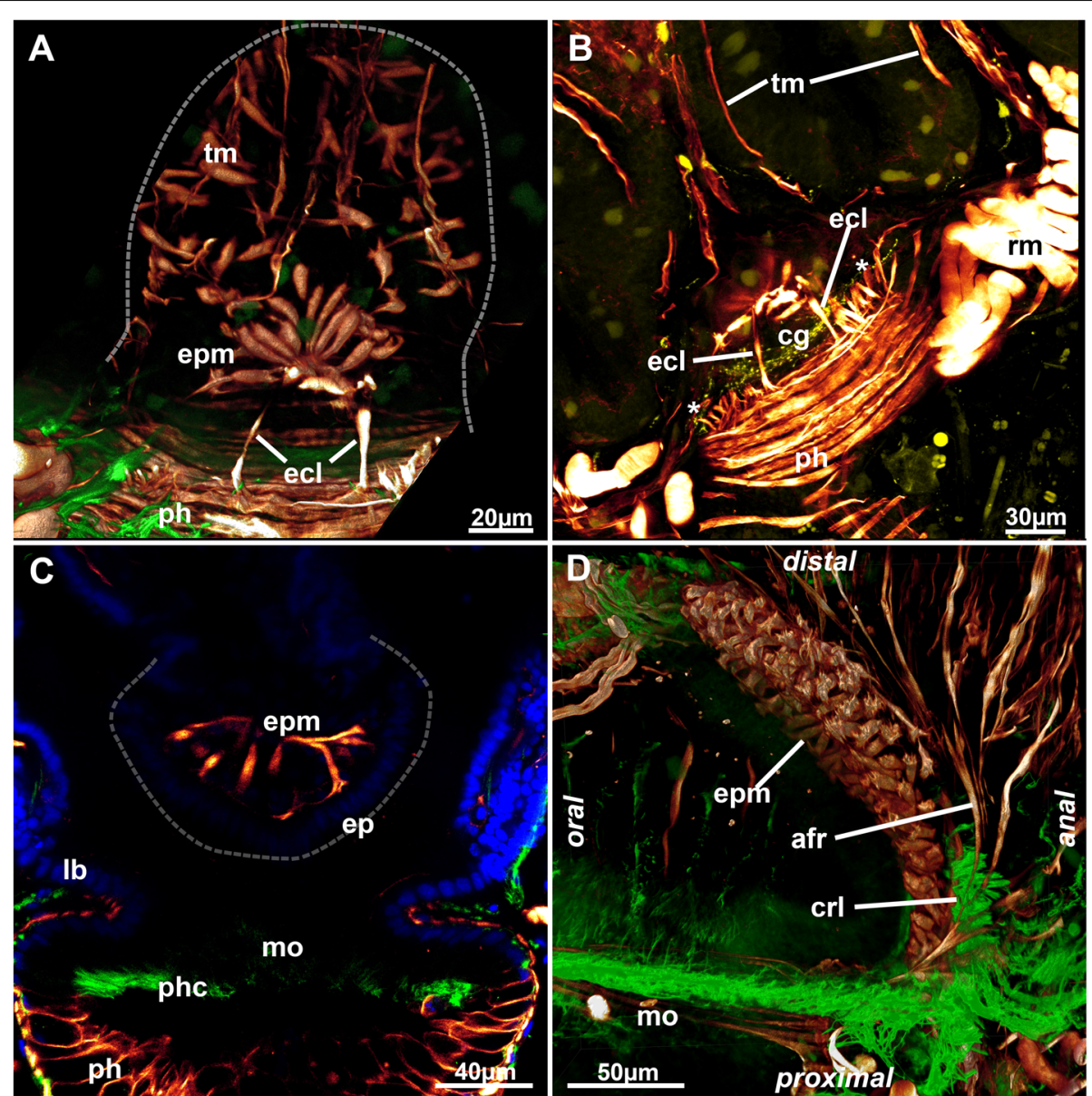

lb
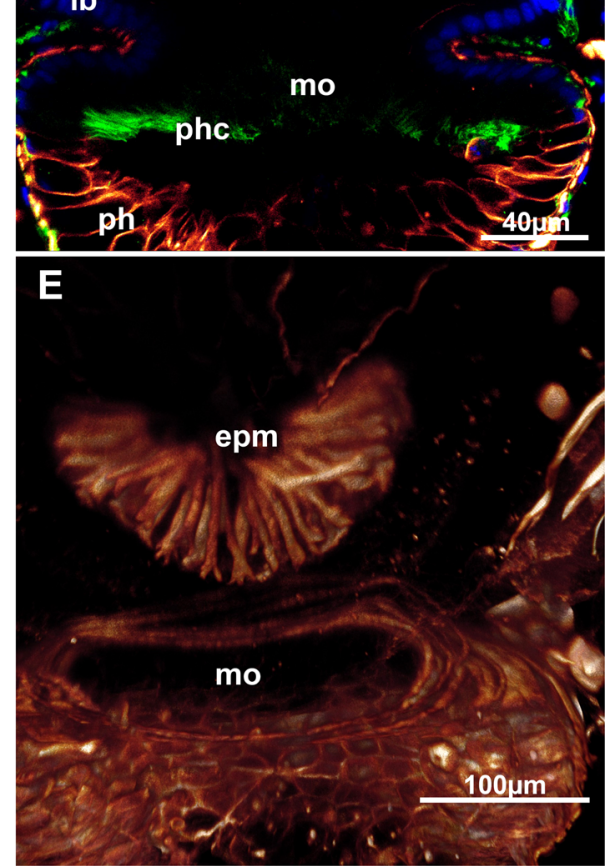

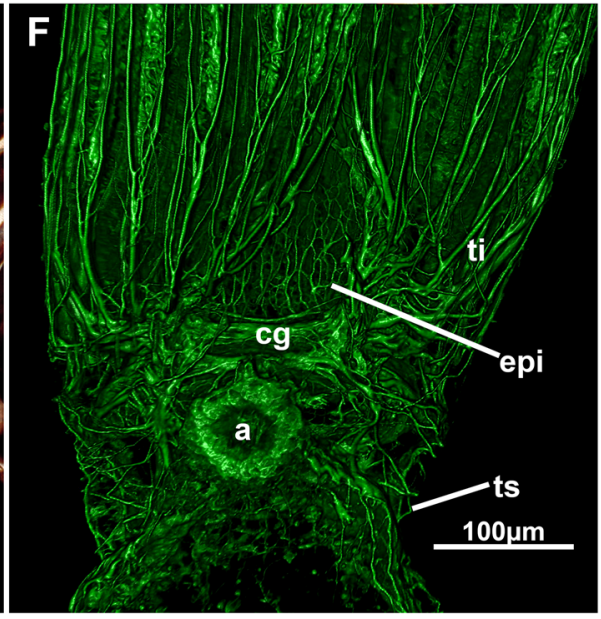

Fig. 6 Epistome myoanatomy and innervation of Stephanella hina. Confocal laser scanning microscopy stacks based on acetylated alpha-tubulin labelling. Volume renderings, projections or optical slices. Acetylated alpha-tubulin in green LUT, f-actin in glow LUT. a Volume rendering of the epistomial musculature from the anal side. Note the lateral epistomial canal muscles. b Maximum projection of the same volume in A showing thin lateral muscle fibres lateral to the epistomial canal muscles. c Optical section through the foregut and the epistome showing individual, smooth muscle fibres crossing. $\mathbf{d}$ Lateral rendering showing epistomial musculature and dense lateral ciliation on their proximo-lateral side. $\mathbf{e}$ Volume rendering of the epistomial musculature. $\mathbf{f}$ Innervation of the epistome. A thin plexus extends directly from the cerebral ganglion. Abbreviations: a - anus, afr - abfrontal muscle root, cg - cerebral ganglion, crl - ciliary ridge laterally of the epistome, ecl - epistome canal muscles, ep - epistome, epi - epistome innervation, epm - epistome musculature, lb. - lophophoral base, mo - mouth opening, ph - pharynx, phc - pharynx ciliation, rm. - retractor muscle, ti - tentacle innervation, tm - tentacle muscles, ts - tentacle sheath 


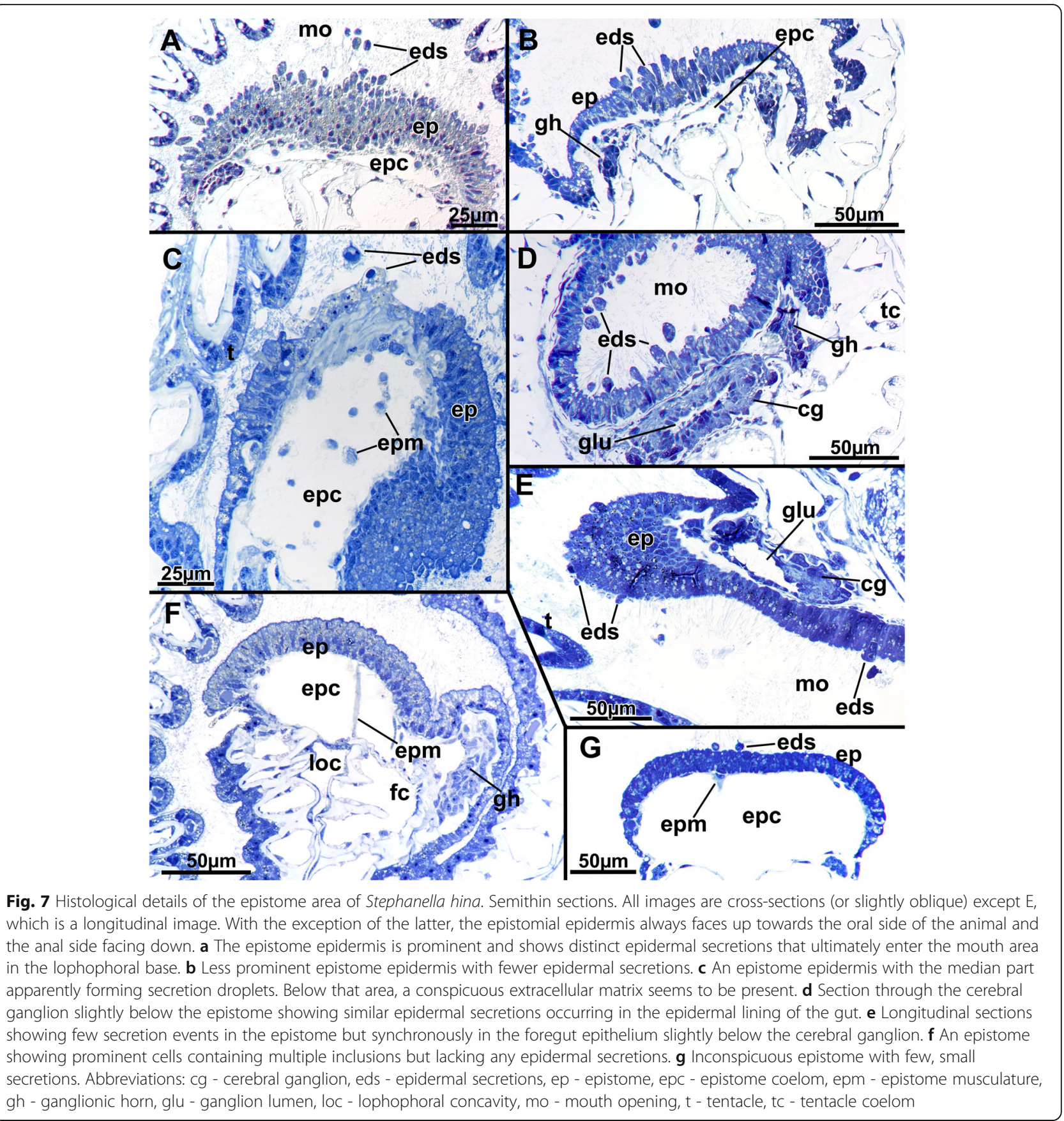

(Fig. 15). The abfrontal muscle begins as a thin thread at the lophophoral base and continues into a broader stack of several muscular areas arranged in a zig-zag manner (Fig. 15d). The remaining abfrontal muscle band extends to the distal tip of the tentacle. In the inner lophophoral concavity, the abfrontal roots converge lateral to the epistome to a single site of origin (Fig. 6d). The frontal muscle band has its roots more distal to that of the abfrontal band in the lophophoral base but does not show any specific rooting in the latter (Fig. 15c, d). It is thinner than the abfrontal muscle and extends along each tentacle as well. Laterally, each tentacle shows a distinct $\mathrm{f}$-actin-rich border (Fig. 15b). With the exception of the epistome, no additional musculature is present on the lophophoral base. The epistome has a series of thick, smooth muscle bundles traversing the epistomial cavity (Figs. 6a, c-e; 15b). In addition, two longitudinal muscle bands are embedded in the lateral lining of the epistomial canal to the anal side of the cerebral ganglion that connects the epistomial coelom with the remaining body cavity (Fig. 6a, b). Several thinner muscle bands appear to run in parallel on the proximo-lateral sides of the 


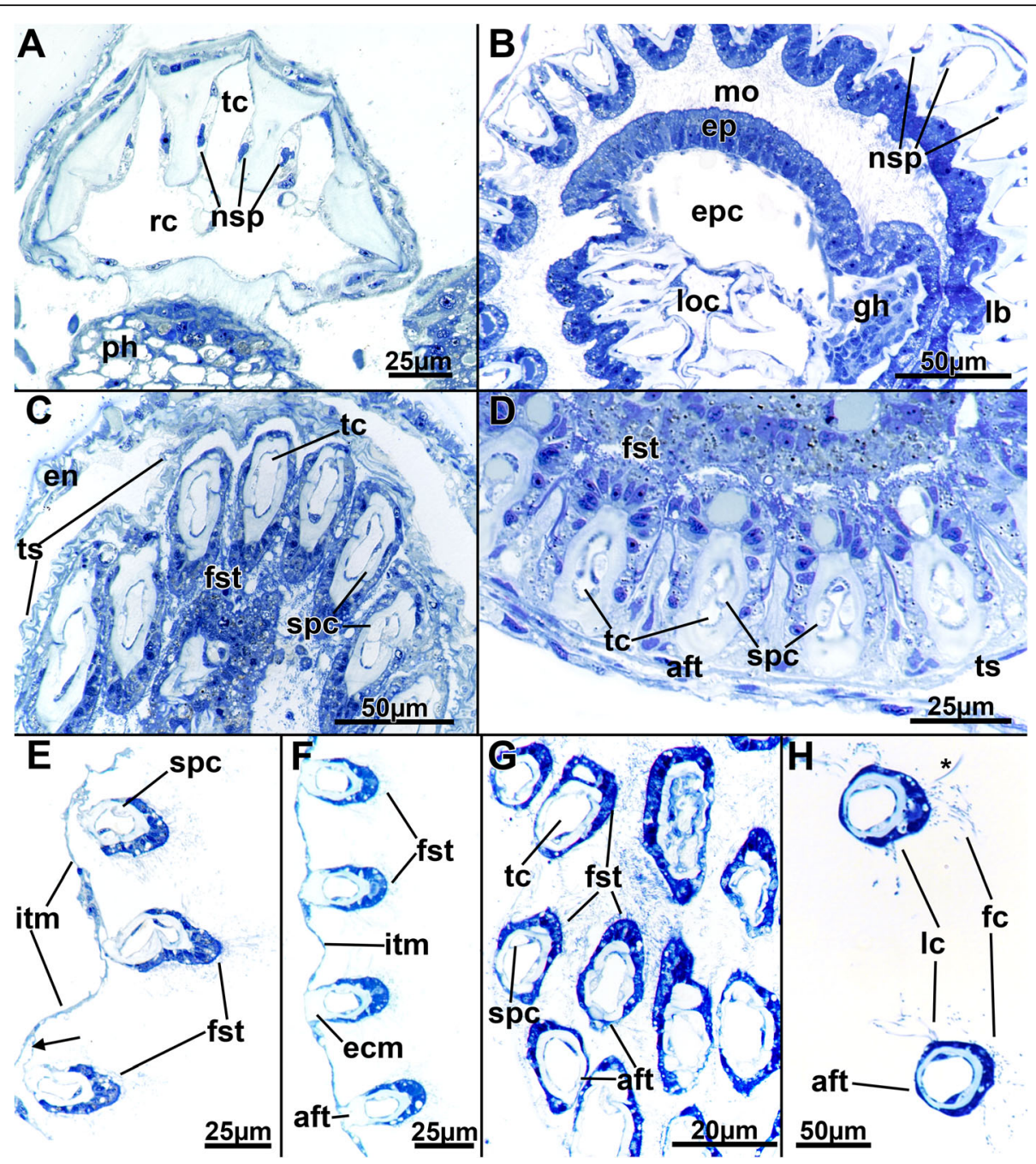

Fig. 8 Histological details of the tentacles of Stephanella hina. Semithin sections. a Longitudinal section of the oral lophophoral base through the ring canal showing extension from the ring canal into the oral tentacles and longitudinally sectioned nuclei of the subperitoneal cells of the tentacles. $\mathbf{b}$ Slightly oblique cross-section of the lophophoral base. The tentacles on the right side are more proximal, with the tentacle coelom still embedded in a common extracellular matrix, whereas the sectioned tentacles on the left show individual tentacles already. The nuclei of the subperitoneal cells are visible on the right side. c Cross-section of retracted tentacles within the tentacle sheath. Note also the subperitoneal cells medially occluding the tentacle coelom in some areas of the retracted positions (right side of the image). $\mathbf{d}$ Close-up of cross-sectioned retracted tentacles showing subperitoneal cells bulging medially towards the tentacle coelom in the longitudinal axis of each tentacle. e \& $\mathbf{f}$ Cross-sections of extended lophophores showing different attachment possibilities of the tentacles to the intertentacular membrane via thin pedicels (e) or with the abfrontal side of the tentacles completely integrated into the membrane $(\mathbf{f})$. $(\mathbf{g} \& \mathbf{h})$ Cross-sections of densely arranged tentacles $(\mathbf{g})$ with a thin epidermal layer always present on the abfrontal side and a thicker epidermal layer on the frontal side. Cilia are mainly located on the lateral and frontal sides of the tentacles (h). Note a thick cilium (asterisk) extending from the upper tentacle in (h), possibly a latero-frontal cilium. Abbreviations: aft - abfrontal side of tentacle, ecm - extracellular matrix, en - endocyst, ep - epistome, epc - epistome coelom, fc - frontal cilia, fst frontal side of tentacle, gh - ganglionic horn, itm - intertentacular membrane, lb. - lophophoral base, Ic - lateral cilia, loc - lophophoral concavity, mo - mouth opening, ph - pharynx, nsp - nuclei of subperitoneal cells, rc - ring canal, spc - subperitoneal cells of tentacles, tc - tentacle coelom, ts - tentacle sheath

ganglion. 6) Retractor muscles are the most prominent and thickest muscles in the zooid. They consist of a series of bundles emerging from a single origin on the body wall that extend to the oral side of the polypide and attach at the lophophoral base, the foregut and parts of the midgut (cardia, caecum) (Fig. 11c). These are exclusively smooth muscle fibres.

\section{Nervous system}

The centre of the nervous system is the cerebral ganglion located at the lophophoral base (Figs. 5; 6f; 7d; $16 \mathrm{~b})$. It is adjacent to the anal side of the pharyngeal wall of the gut. The ganglion contains a small cavity (Fig. 7d) that is shifted towards the pharyngeal wall, whereas the neuronal tissue is concentrated on the anal side in the 


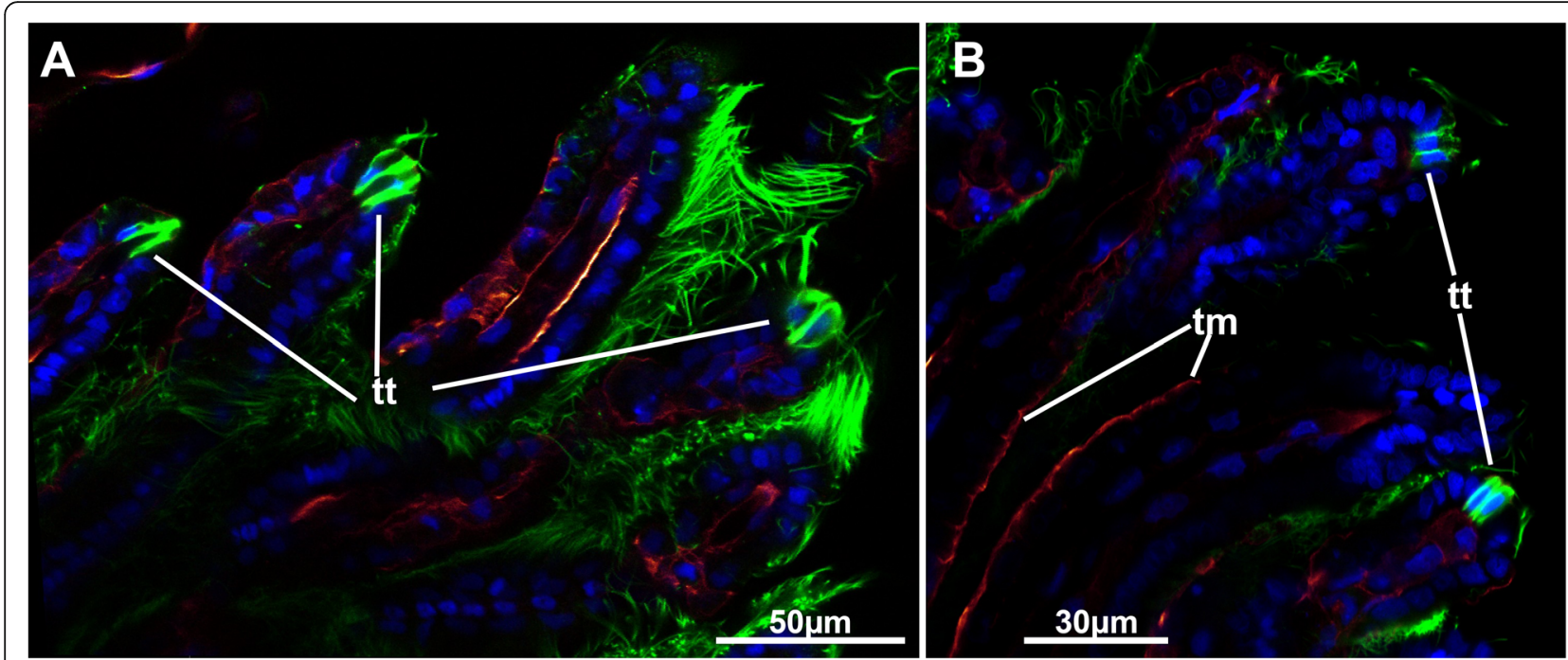

Fig. 9 Tentacle tips of Stephanella hina. Confocal laser scanning microscopy stacks based on acetylated alpha-tubulin labelling. Optical slices. Acetylated alpha-tubulin in green LUT, f-actin in glow LUT. a \& $\mathbf{b}$ Different sections of tentacle tips showing distinct ciliary tips at the distal ends of the tentacles. Abbreviations: $\mathrm{tm}$ - tentacle muscle, $\mathrm{tt}$ - tentacle tip

form of a croissant. Lateral to the ganglion, two ganglionic horns or extensions emerge that protrude distally towards the short lophophoral arms. These are slightly curved, bending medially into the direction of the inner arc of tentacles into the lophophoral concavity towards the epistome (Figs. 5; 17).

A circum-oral nerve ring $(\mathrm{CON})$ emanates from both lateral sides of the ganglion and encircles the mouth opening. From the ganglion and the $\mathrm{CON}$, intertentacular neurite bundles, the radial nerves, emerge from where most of the tentacle neurite bundles branch off (Figs. 5; 16b; 18; 19a-c). Additional medio-frontal neurite bundles branch from paired roots that emerge either directly from the $\mathrm{CON}$ or from the proximal areas of the radial nerves (Figs. 18; 19a, b). In total, there are four distinct tentacle neurite bundles: The medio-frontal neurite bundles emerge most proximally with several roots that merge in the median plane of each tentacle to form a single neurite bundle for each tentacle (Fig. 19a). The roots commonly show several lateral interconnections between the tentacles. The remaining tentacle neurite bundles arise from the prominent intertentacular radial nerves. First, at least two thin roots, one more proximal and another more distal, branch of the radial nerve and traverse frontally to form a latero-frontal neurite bundle on each side of a tentacle, next to the medio-frontal bundle (Figs. 18c; 19a-c). More distally, the radial nerve branches into two thicker bundles that extend to the proximo-lateral and abfrontal sides of each tentacle (Figs. 18a; 19a-c). On each tentacle, these paired latero-abfrontal neurite bundle roots merge further distally into a single abfrontal neurite bundle (Fig. 18a).
Additional radial neurite bundles are present at the lophophoral base. These branch off the root of the radial nerve and extend more proximally towards the outer margin of the lophophoral base (Fig. 19). At the outer margin of the lophophoral base, these bundles frequently lead to a series of two to three perikarya in the epidermal layer of the outer lophophoral base (Fig. 19d, e). Turning distally, the remaining neurite bundles of the additional radial nerve innervate the outer lophophoral base (Fig. 19a-c).

Some samples show distinct neurite bundles extending from the cerebral ganglion into the epistome. These bundles branch directly from the cerebral ganglion orodistally into the epitome as a fine plexus (Fig. 6f).

In addition to lophophoral innervation, additional neurite bundles extend from the cerebral ganglion and the $\mathrm{CON}$ to the visceral parts and the tentacle sheath. The digestive tract shows a diffuse nerve plexus that is most concentrated in the foregut until the cardiac valve (Figs. 16a, b; 18b; 19). There are no distinct concentrated neurite bundles present in the foregut. Innervation of the midgut is rather sparse, with only a few neurite bundles associated with the gut wall. In the caecum, these are associated with the circular muscle bundles (Fig. 16c). No distinct innervation of the intestine could be found. Presumptive sensory cells have been detected in the foregut, cardia and anal areas, emerging from the nerve plexus wedged into the remaining cells of the gut epithelium (Fig. 16d, e).

The tentacle sheath shows a diffuse nerve plexus without any particular concentrated neurite bundles, similar to the visceral innervation. The plexus extends over the entire tentacle sheath (Figs. 14b; 16a, b). Close to the 


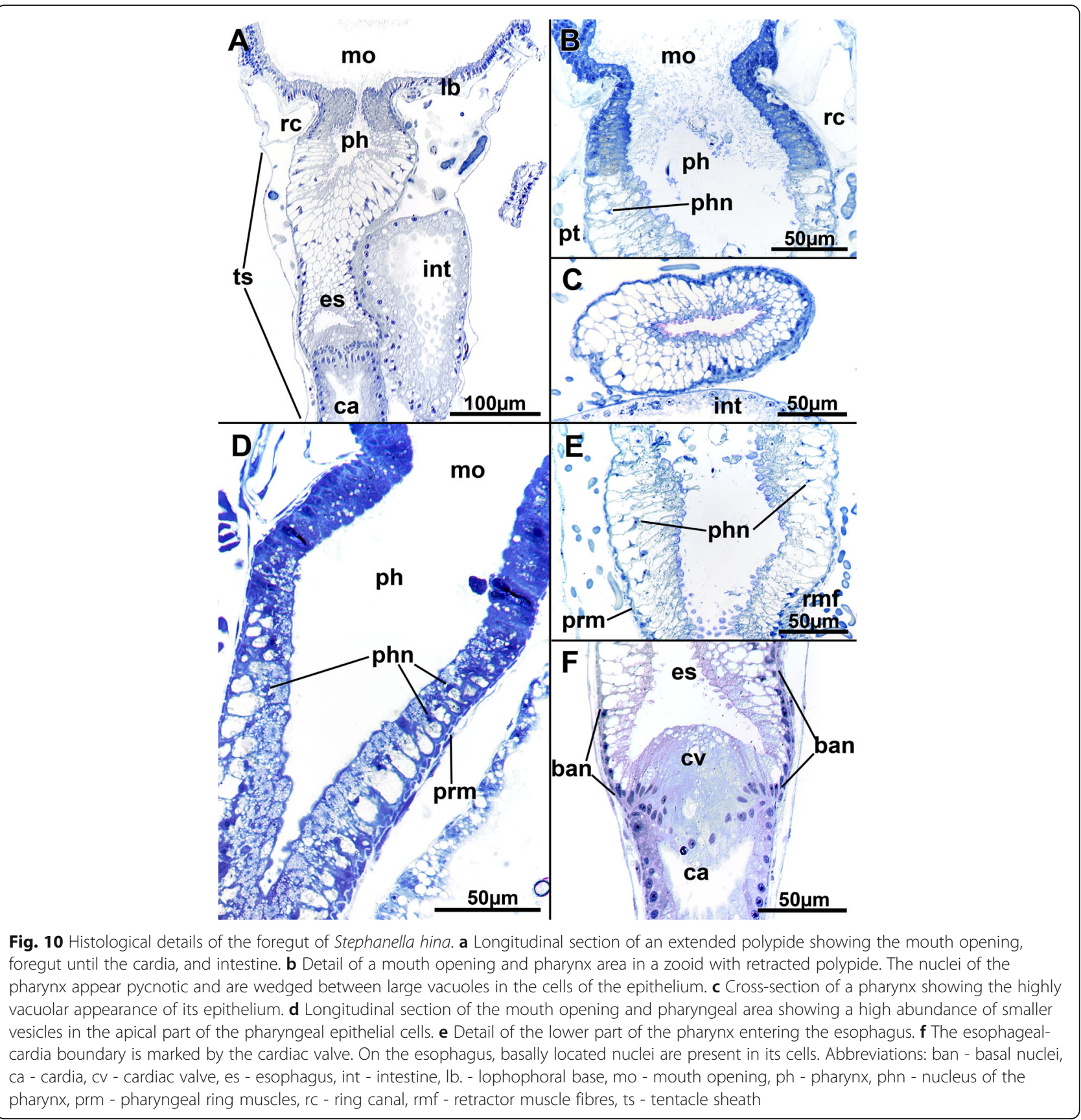

vestibular area, neurite bundles extend via the duplicature bands into the body wall plexus (Figs. 4a, b; 14d).

\section{Discussion}

The general morphology of Stephanella is similar to other phylactolaemate species (see [4]); nevertheless, several fine details, particularly of the lophophore structure, are strikingly different from those of any other species.

\section{Epidermis and vestibular wall}

The epidermal structure has seldom been used for comparative analyses. Instead, the glandular morphology of the typical gelatinous families lophopodids, cristatellids and pectinatellids was previously recognized as important for its systematic implications [19]. In addition to specific glandular patches, the so-called white spots, that are restricted to a small number of species [20], two different gland types are generally distinguished: the 

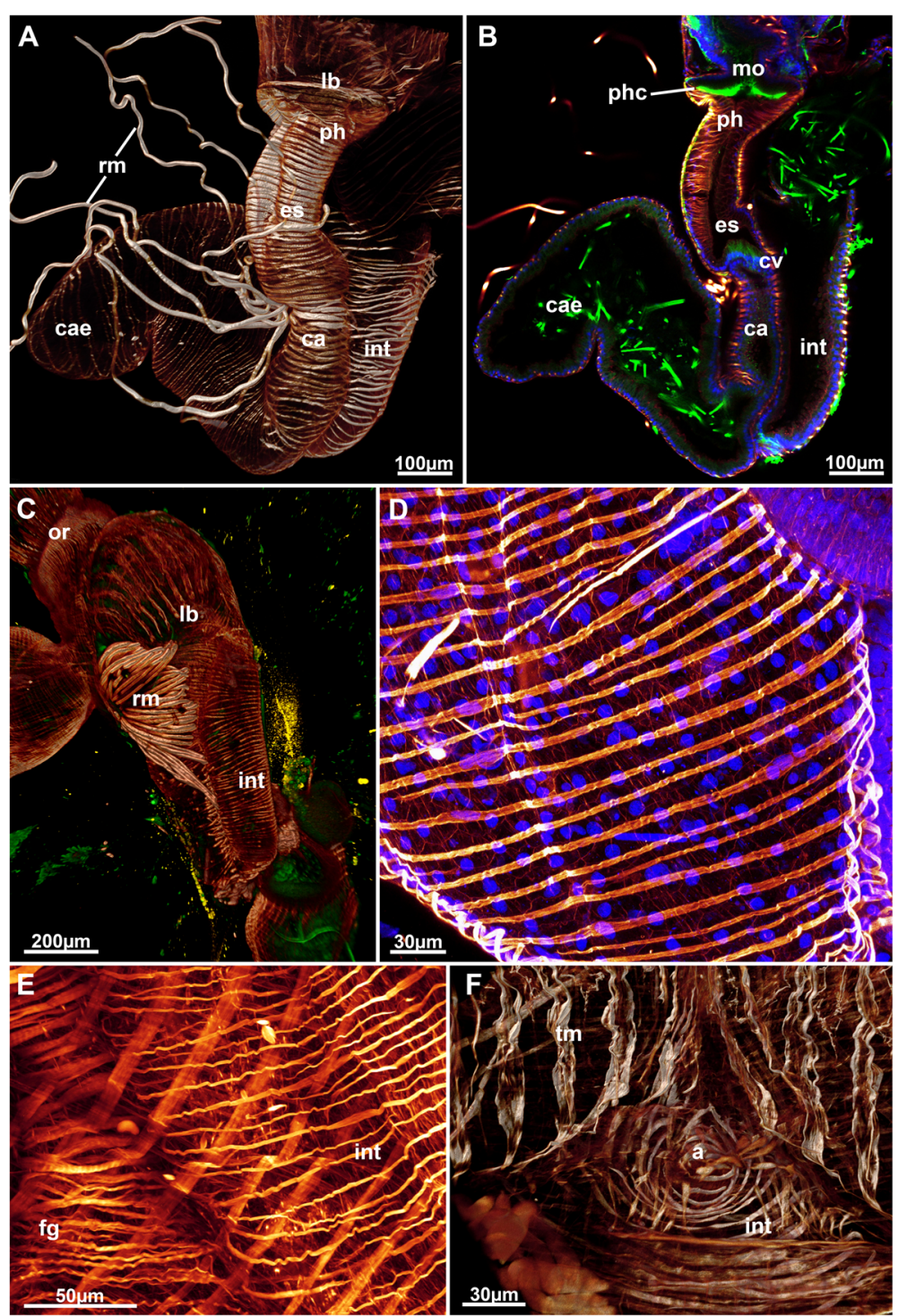

Fig. 11 Muscular system of the digestive tract of Stephanella hina. Confocal laser scanning microscopy stacks based on f-actin labelling. Volume renderings, projections or optical slices. F-actin in glow LUT. a Volume rendering of a dissected zooid showing the major areas of the gut. $\mathbf{b}$ Optical section of the data set in A showing the border between the esophagus and the cardia. $\mathbf{c}$ Volume rendering showing the fanned retractor muscle inserting into various sites of the oral digestive tract. $\mathbf{d}$ Detail of the smooth circular muscles of the caecum. e Detail of the circular muscles of the foregut showing cross-striation and the smooth hindgut, the intestine. $\mathbf{f}$ View of the circular muscles of the anus. Abbreviations: a - anus, ca - cardia, cae - caecum, cv - cardiac valve, es - esophagus, fg - foregut, int - intestine, lb. - lophophoral base, mo mouth opening, or - orifice, ph - pharynx, phc - pharynx ciliation, rm. - retractor muscle, tm - tentacle muscles

vacuolar type and the alveolar type. The former are epithelial cells containing a single large vacuole, whereas the latter have numerous smaller vesicles throughout the cytoplasm. Vacuolar cells are also present in Stephanella hina, whereas distinct alveolar cells could not be identified in the current study. In addition to large vacuolar inclusions, smaller translucent vesicular structures were found in S. hina, but these appeared to also occur within vacuolar gland cells. In general, the high heterogeneity of the endocyst structure in S. hina remains poorly understood. It is possible that the presence and thickness of the ectocyst tube is reflected in the glandular composition of the epidermis, especially since the ectocyst is, for the most part, not connected to the epidermis and can also be removed without greater harm to the zooid [14]. Since the ectocyst structure is a diagnostic character for genus classification in plumatellids, the largest taxon of Phylactolaemata, the epidermal structure appears promising for future comparative analyses over the entire range of families and within genera of a 


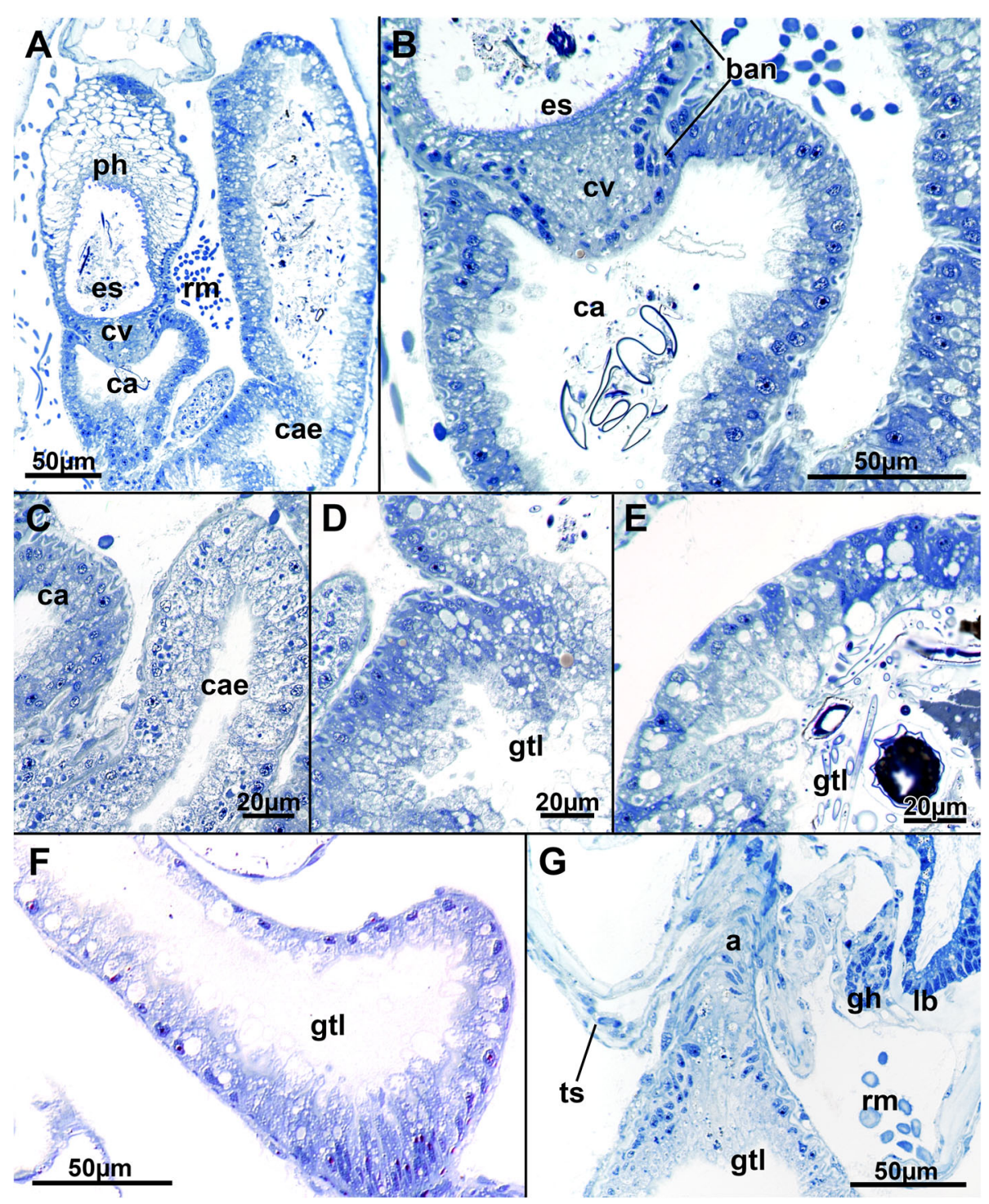

Fig. 12 Histological details of the mid- and hindgut of Stephanella hina. a Longitudinal section of a polypide showing the transition of the esophagus to the cardia and parts of the caecum. $\mathbf{b}$ Close-up of the cardiac valve and cells of the cardia. c-e Detailed images of the cellular architecture of the caecum epithelium showing its variable cellular architecture. $\mathbf{f}$ Details of the cells of the intestine. $\mathbf{g}$ Detail of the anal area entering the tentacle sheath. Abbreviations: a - anus, ban - basal nuclei, ca - cardia, cae - caecum, cv - cardiac valve, es - esophagus, gh ganglion horn, gtl - gut lumen, lb. - lophophoral base, ph - pharynx, rm. - retractor muscles, ts - tentacle sheath

specific family, especially in regard to ultrastructure, which was analysed in only a few studies $[21,22]$ and has never been the specific focus of any.

Likewise, the vestibular wall structure also remains poorly studied (see $[4,19])$. It is always a prominent, thickened epithelium as encountered in S. hina. With the exception of Cristatella mucedo, the integration of glandular cells into the vestibular wall has not been described [19]. Stephanella hina shows characteristic, large vacuolar cells (this study), which show little similarity to the glandular cells of $C$. mucedo. In addition, positive anti-acetylated alpha tubulin staining has never been described in this structure for any other phylactolaemate (see ICC studies on phylactolaemates, e.g., [20, 23-25]). The encountered connection with neurite bundles indicates that these cells might be neurosecretory in S. hina. In summary, these appear unique, if not autapomorphic, to S. hina.

\section{Lophophore}

Phylactolaemates typically possess a horseshoe-shaped lophophore with an epistome at its base protruding over the mouth opening from the anal side $[17,26]$. The coelomic system of the phylactolaemate lophophore shows 


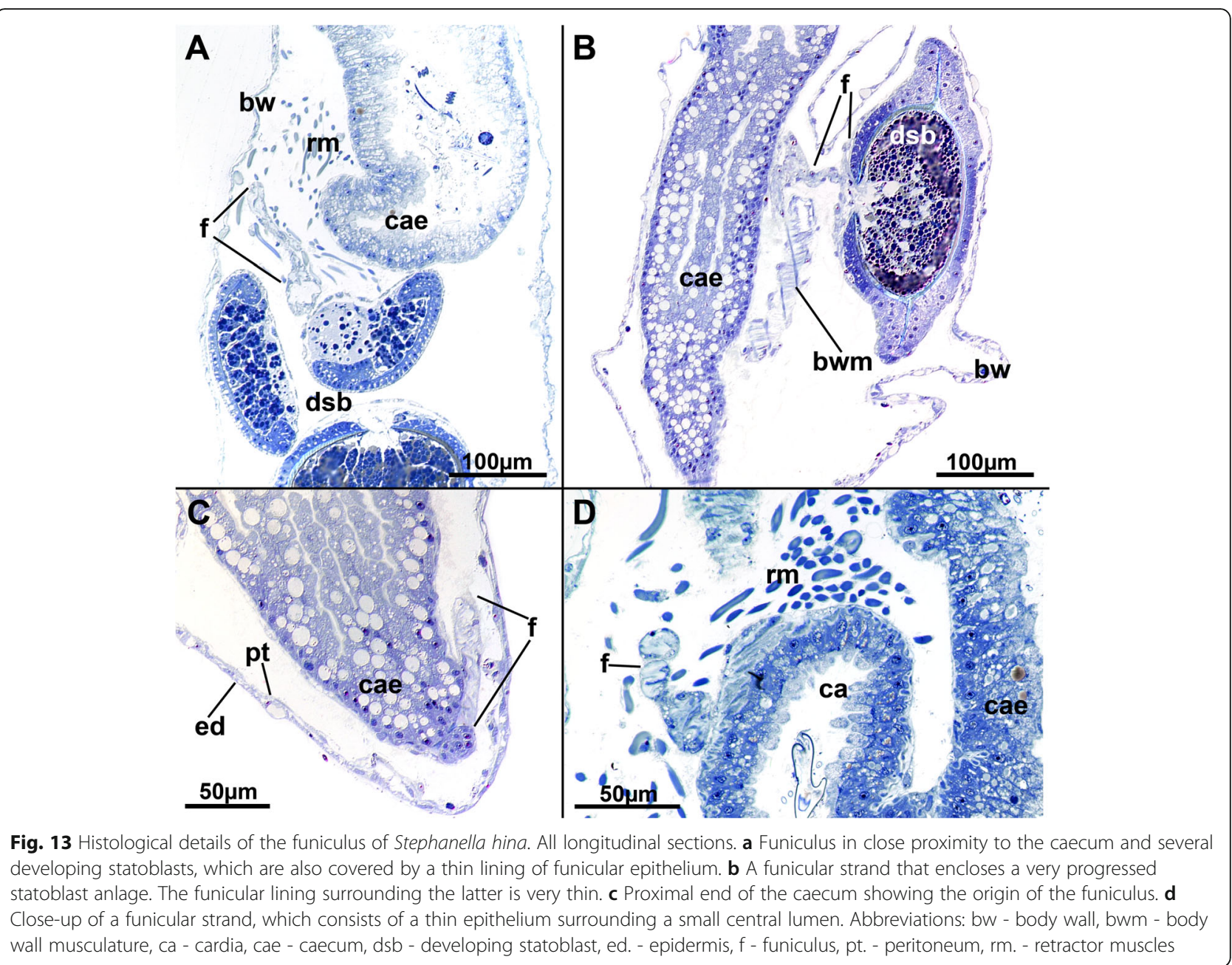

three distinct canals: a median epistomial canal, which extends from the inner peritoneal lining of the gut shanks into the epistome, the ring canal, which is a short canal supplying the oral tentacles of the lophophore, and the forked canal, which interconnects the cavities of the innermost tentacle row in the lophophoral concavity. Unique to Stephanella hina is the lack of a distinct, continuous forked canal. In all other phylactolaemates, the latter commences on the lateral, proximal sides of the cerebral ganglion as ciliated openings that lead into two ducts that medially fuse in the distal direction. This medial fusion of the ciliated ducts arches directly above the epistomial coelomic extension located above the cerebral ganglion $[17,22,27,28]$. The few tentacles in the inner lophophoral concavity are supplied by the forked canal. The general layout in S. hina is similar to ciliary patches at the openings of the forked canal ducts, but in S. hina, the coelomic cavities do not fuse at the terminal or median ends.

\section{Epistome}

The epistome structure was most recently studied in several phylactolaemate species $[17,21,22]$ and always consists of a highly prismatic epithelium of mostly ciliated cells. To date, distinct holocrine secretion via the epistome epithelium (or the underlying gut epithelium surrounding the mouth opening), as encountered in the current study on S. hina, has not been reported in any other species. Interestingly, the distribution of these secretory processes correlates with the reddish coloration of the same areas in live animals [14]. Colorations or tinges of the epistome are common in phylactolaemates, e.g., with Cristatella mucedo having a brownish hue (and Pectinatella magnifica a bright red coloration in the epistome, e.g., [3, 4]). In such prominent forms with very large zooidal sizes, these colorations are very evident. However, distinct darker hues are also present in other phylactolaemates, such as plumatellids. 

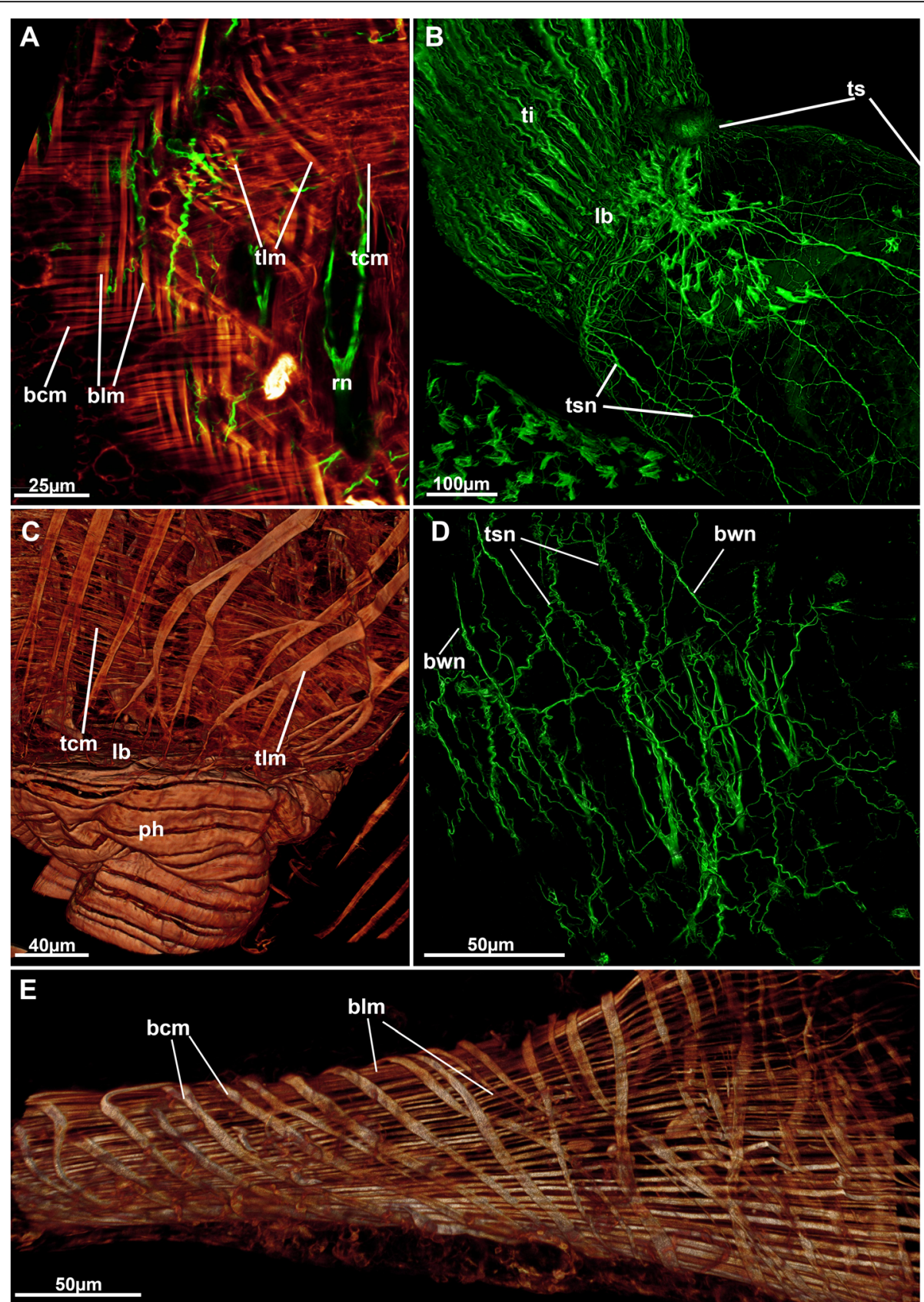

Fig. 14 Neuro-muscular system of the peripheral areas of Stephanella hina. Confocal laser scanning microscopy stacks based on acetylated alphatubulin labelling. Volume renderings, projections or optical slices. Acetylated alpha-tubulin in green LUT, f-actin in glow LUT. a Optical section showing body wall musculature on the left and tentacle sheath musculature on the right. Both show thick longitudinal fibres and thinner circular fibres. $\mathbf{b}$ Overview of an extended polypide showing diffuse tentacle sheath innervation in form of a plexus. c Tentacle sheath musculature of a retracted polypide showing both circular and longitudinal fibres close to the lophophoral base. $\mathbf{d}$ Diffuse nerve plexus of the body wall and partially underlying tentacle sheath nervous plexus. e Orthogonal grid of the body wall musculature in the thin, 'stolon'-like parts of the colony. Abbreviations: bcm - body wall circular muscle, blm - body wall longitudinal muscle, bwn - body wall nerves, lb. - lophophoral base, ph pharynx, rn - radial nerve, tcm - tentacle sheath circular muscle, ti - tentacle innervation, tlm - tentacle sheath longitudinal muscle, ts - tentacle sheath, tsn - tentacle sheath innervation

Excretion is a little studied process in bryozoans and often seems to be associated with coelomocytes [2]. The secretory mechanism found in Stephanella hina in the present study seems to be newly discovered but poorly understood. The high variability of the epistome structure observed in this study indicates that this process is probably influenced by external factors such as (e.g., physical or temperature-induced) stress. Likewise, the 


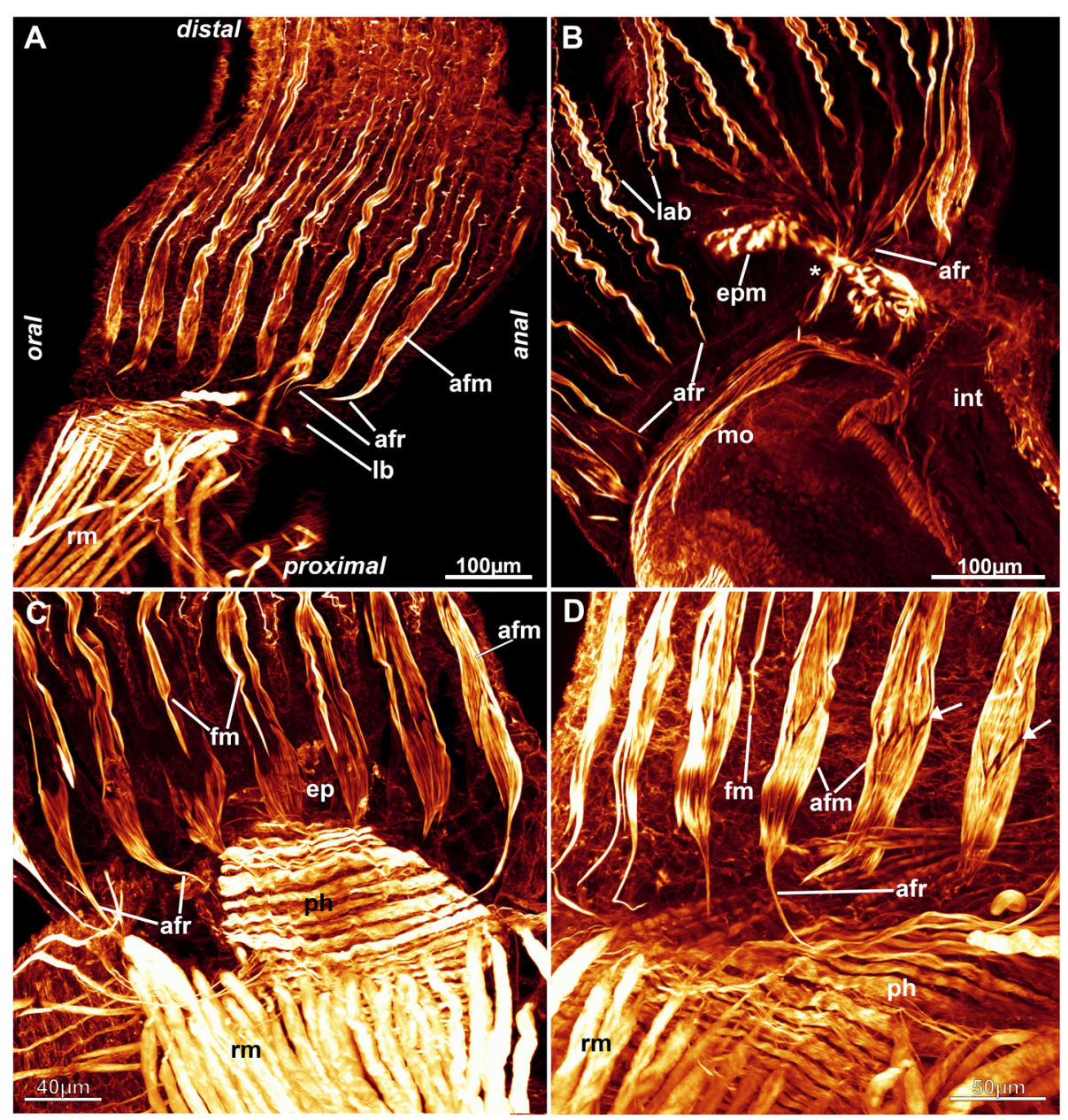

Fig. 15 Muscular system of the lophophore of Stephanella hina. Confocal laser scanning microscopy stacks based on f-actin labelling. Volume renderings, projections or optical slices. F-actin in glow LUT. a Lateral view of a retracted polypide showing the foregut and retractor muscle. $\mathbf{b}$ Lateral view of the abfrontal muscle roots in the inner lophophoral concavity where the roots merge lateral to the epistome (asterisk). c Close up from the anal side showing tentacle muscles. $\mathbf{d}$ Details of the proximal abfrontal muscle roots. Note the zig-zag arrangement of the abfrontal muscle bands (arrows). Abbreviations: afm - abfrontal muscle band, afr - abfrontal muscle root, ep - epistome, epm - epistome musculature, fm - frontal muscle, int - intestine, lab - lateral actin-rich borders of tentacles, lb. -lophophore base, mo - mouth opening, ph - pharynx, rm. retractor muscle

coelomocyte abundance in S. hina appears to be stressrelated [Schwaha, personal observation].

\section{Digestive tract}

The digestive tract of $S$. hina is similar to that of other phylactolaemates $[2,17]$. A persistent problem is the terminology used for and homology of the foregut. In the last summary on bryozoan digestive systems, the phylactolaemate pharynx was always considered the first area of the foregut that bears cilia [29]. Consequently, only the short area surrounding the mouth opening should be addressed as the 'pharynx' in S. hina and the remaining, particularly vacuolated epithelium as the esophagus until the cardiac valve. However, several studies (including the present study) frequently label the upper vacuolated area the pharynx (see [21]). This mostly results from the terminology applied to myolaemates, which are characterized by a myoepithelial, suction pharynx also characterized by vacuolated cells $[2$, 29]. Similar to S. hina, only a short area close to the mouth opening carries cilia, whereas most of the vacuolated area lacks them. Both, however, are myoepithelial and show distinct cross-striated muscle filaments in their lateral linings. Beyond the vacuolated cells, the esophagus of myolaemates is not myoepithelial or vacuolated. Hence, the mixture of different cytological characteristics makes it difficult to truly assign the parts of the gut.

The typical ciliated pharyngeal area of other phylactolaemates is frequently longer than in S. hina [29], whereas the vacuolated area of the foregut has either been described with basally located nuclei and single 

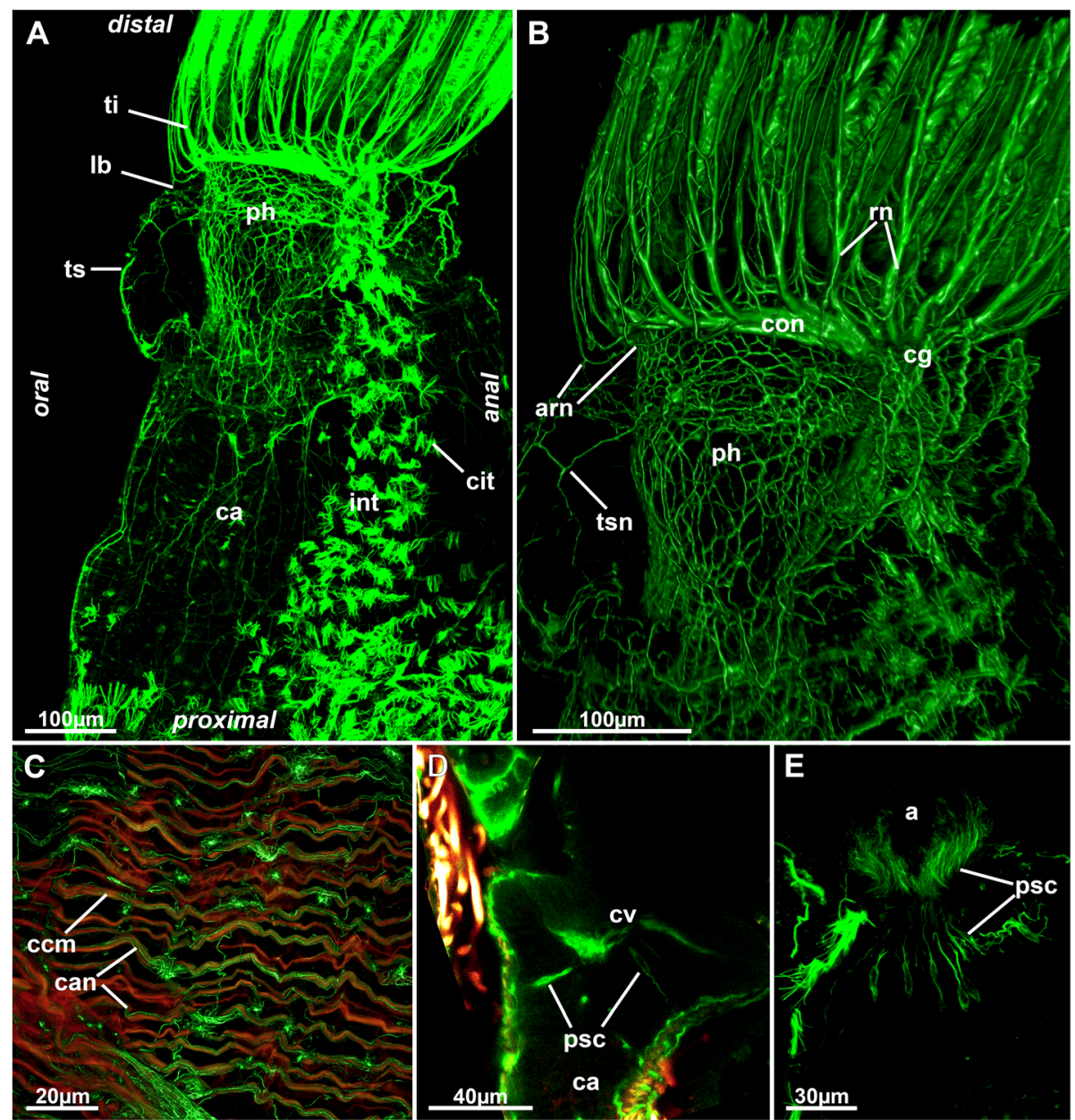

Fig. 16 Nervous system of the digestive system of Stephanella hina. Confocal laser scanning microscopy stacks based on acetylated alpha-tubulin labelling. Volume renderings, projection or optical slices. Acetylated alpha-tubulin in green LUT, f-actin in glow LUT. a General overview of an extended polypide showing dense innervation of the foregut. Note also the dense ciliary bundles on the anal side of the intestine. $\mathbf{b}$ Details of the foregut shown in A. c Innervation of the caecum. $\mathbf{d}$ Optical section of the foregut-cardia transition showing few presumptive sensory cells projecting into the digestive epithelium. e Presumptive sensory cells in the lining of the intestinal wall close to the anus. Abbreviations: a - anus, arn - additional radial nerve, ca - cardia, can - caecum innervation, ccm - caecal muscles, cg - cerebral ganglion, cit - ciliary tufts, con - circumoral nerve ring, cv - cardiac valve, int - intestine, lb. - lophophoral base, ph - pharynx, psc - presumed sensory cells, rn - radial nerve, ti tentacle innervation, ts - tentacle sheath, tsn - tentacle sheath innervation

large vacuoles [17] or, as in S. hina, with nuclei in the middle of the cells with vacuoles on the base and distal areas [21]. As shown in the present study, the nuclei are very small and appear not very active, suggesting that the foregut is mere a mechanical transport tube (see also [29]). In the plumatellid Hyalinella punctata, presumptive sensory cells are also embedded into this area of the gut [25], but these were not very abundant in S. hina. The remaining gut of $S$. hina shows no distinct differences from any other phylactolaemate.

Additional studies should comparatively analyse all six major phylactolaemate families regarding the anatomy and cytological specifications of the foregut. This should aid in redefining the terminology in terms of more criteria than just ciliation and also investigate whether morphological details of the gut might have any systematic or phylogenetic value.

\section{Myoanatomy}

The myoanatomy of phylactolaemates has been studied recently with f-actin staining in four of its six major families, including Plumatellidae and Fredericellidae by Schwaha \& Wanninger [30] and Pectinatellidae and Cristatellidae by Gawin et al. [31]. The current investigation on the fifth family, Stephanellidae, with its current sole representative Stephanella hina, shows that the main muscular systems are very similar to previous descriptions. Concerning the six abovementioned muscular systems, the following can be summarized. 1) The body wall possesses a regular muscular grid as present in 


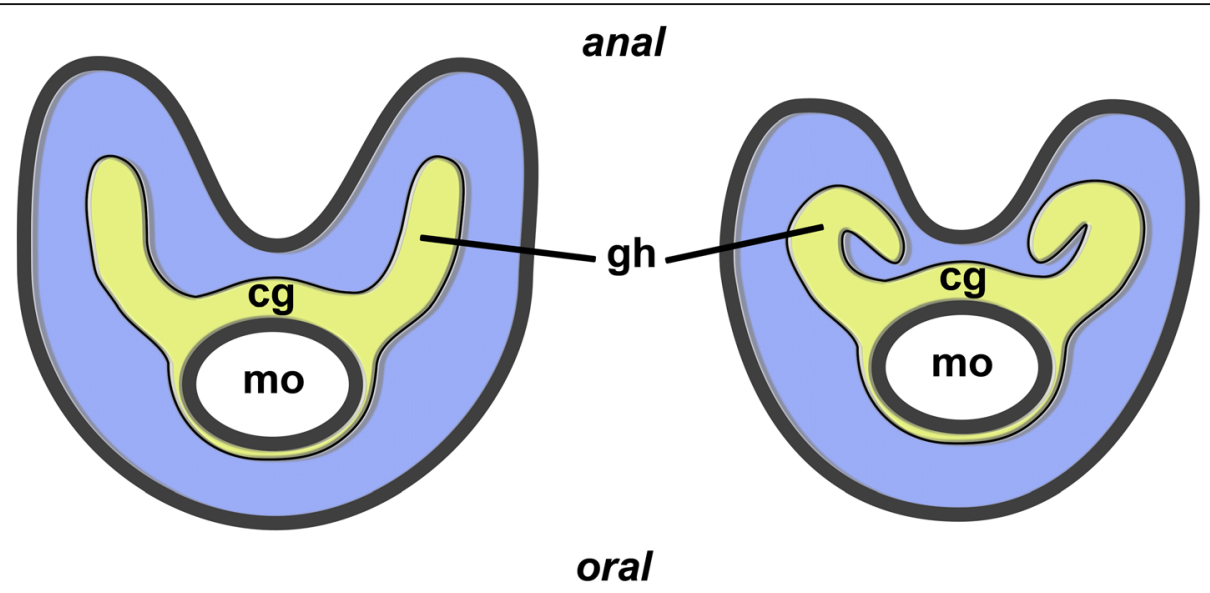

Fig. 17 Schematic drawing of the neuronal structures of the lophophoral base of most phylactolaemates (left) and Stephanella hina (right). Abbreviations; cg - cerebral ganglion, gh - ganglionic horn, mo - mouth opening

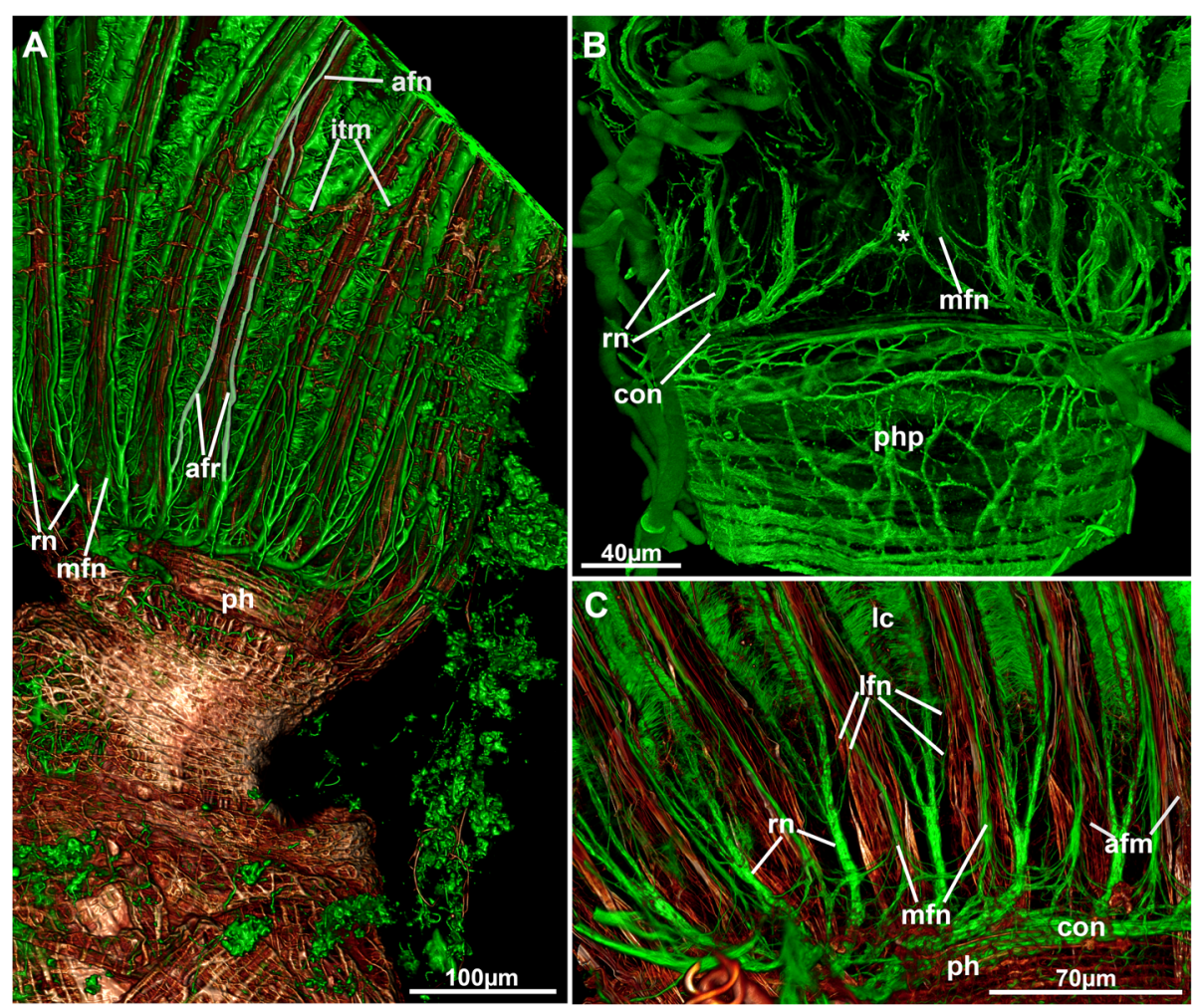

Fig. 18 Overview of the lophophoral nervous system of Stephanella hina. Confocal laser scanning microscopy stacks based on acetylated alphatubulin labelling. Volume renderings. Acetylated alpha-tubulin in green LUT, f-actin in glow LUT. a Volume rendering showing an overview of the lophophoral nervous system. One of the abfrontal neurite bundles and its roots have been highlighted in white. $\mathbf{b}$ Oral view of the circum-oral nerve ring closing medially on the oral side (asterisk). c Close-up of the lophophoral base showing radial nerves and their position with respect to the abfrontal tentacle muscle bands. Abbreviations: afm - abfrontal muscle band, afn - abfrontal neurite bundle, afr - abfrontal neurite bundle root, con - circum-oral nerve ring, itm - distal border of the intertentacular membrane, lc - lateral cilia, Ifn - latero-frontal neurites, mfn - mediofrontal neurite bundle, ph - pharynx, php - pharyngeal plexus, rn - radial nerve 

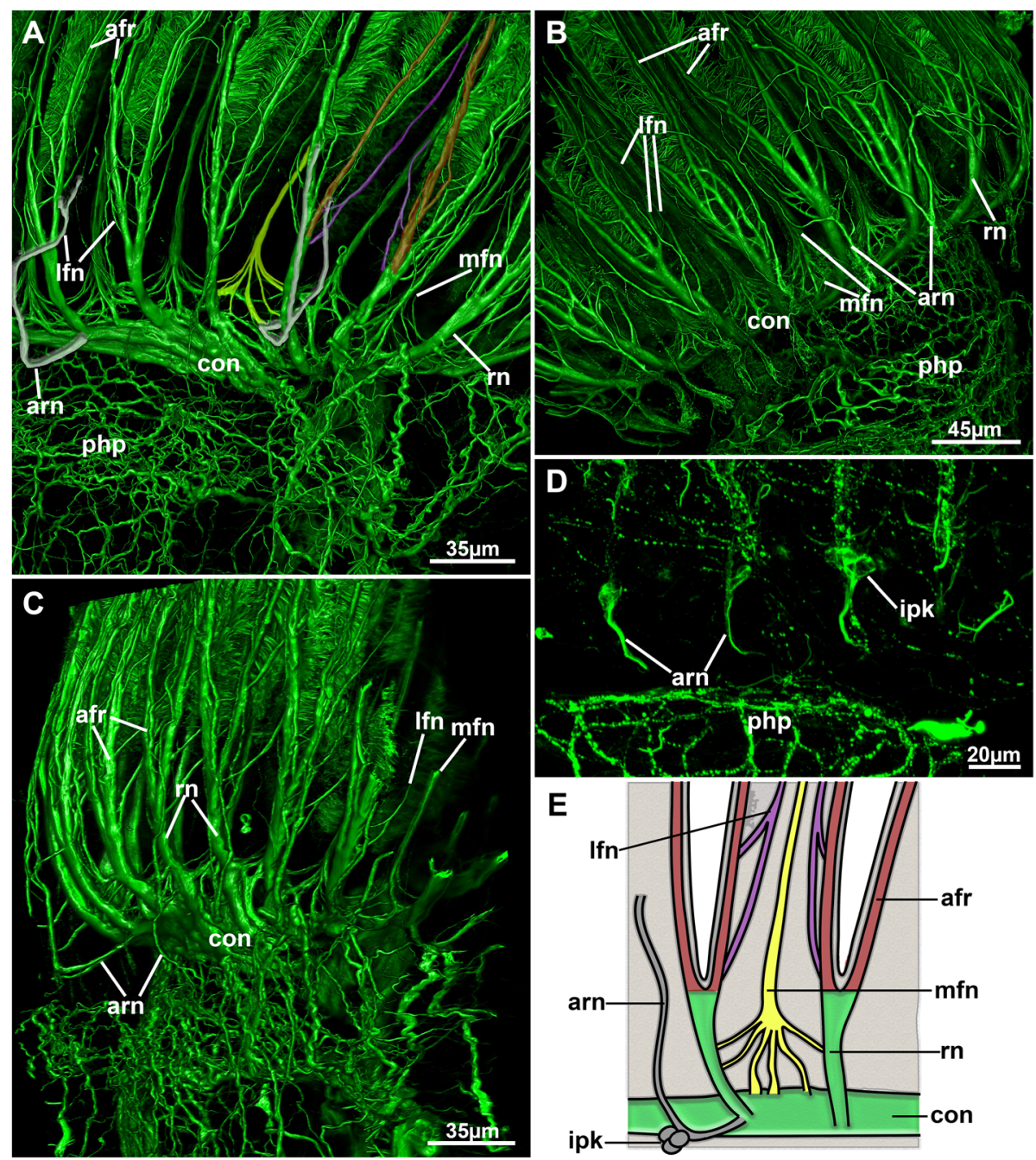

Fig. 19 Detail of the tentacle innervation of Stephanella hina. a Lateral view of the lophophoral base showing the main tentacle neurite branches. One medio-frontal neurite bundle has been marked in yellow, one latero-frontal pair in purple, one pair of abfrontal neurite bundle roots in red and two additional radial neurite bundles in grey. $\mathbf{b}$ Similar view as in A showing major neurite bundle origins from the circum-oral nerve ring. c Lateral view of the lophophoral base showing the traversal of the additional radial nerve/neurite bundle supplying the outer lophophoral base. $\mathbf{d} \& \mathbf{e}$ Intertentacular perikarya at the additional radial neurite bundle. $\mathbf{d}$ Optical section. e Schematic drawing of the main tentacle neurite bundles. Abbreviations: afr - abfrontal neurite bundle roots, arn - additional radial nerve/neurite bundle, con - circum-oral nerve ring, ipk - intertentacular perikarya, ph - pharynx, Ifn - latero-frontal neurite bundles, $\mathrm{mfn}$ - medio-frontal neurite bundle, php - pharyngeal plexus, rn - radial nerve

other phylactolaemates [2, 4]. A diagonal muscle layer, as found in Pectinatella or lophopodids [31], was not found. Hence, a regular orthogonal grid is most likely the ancestral condition. 2) The apertural muscles with duplicature bands and vestibular dilatators are in accordance with most previous descriptions of phylactolaemates $[15,17]$. Accordingly, since the duplicature bands attach to the distal tentacle sheath in S. hina, the situation is similar to that of most phylactolaemates except lophopodids where the bands attach at the diaphragmatic sphincter [15]. Hence, the more ubiquitous insertion of duplicature bands at the tentacle sheath rather than the diaphragm appears to be the ancestral condition for phylactolaemates. This is also supported in non-phylactolaemates where the bands always insert at the tentacle sheath [2]. The insertion area at the diaphragm in reported lophopodids is probably a derived and apomorphic feature. Most bryozoans, including many phylactolaemates, have a pronounced vestibular wall area, which, however, is little pronounced in S. hina. Hence, the differentiation of the diaphragmatic sphincter structures is not as evident as in other species (see [30, 31]).

3) The tentacle sheath muscles comprise more prominent longitudinal and circular muscles. The arrangement thus reflects the general arrangement of the body 
wall musculature, as also seen in S. hina. This supports the notion that a regular grid of orthogonal musculature is the ancestral condition for phylactolaemates (see [17, $30,31])$. The condition of plumatellids solely bearing longitudinal muscles in the tentacle sheath is thus probably derived, similar to the remaining bryozoans, which also usually only possess longitudinal muscle fibres in the tentacle sheath $[2,17]$. 4) The digestive tract is similar to that in other described phylactolaemates (see [17, $30])$ in that it is supported only by circular muscles. No longitudinal muscle fibres were found, as indicated for the lophopodid Asajirella gelatinosa [21]. In contrast to other species, $S$. hina has smooth muscle fibres in the caecum lining, which is striated in other forms (see above citations). In addition, the arrangement of the muscle bands is very dense in other phylactolaemates, whereas $S$. hina shows a rather loose pattern, particularly in the caecum. In contrast to all other analysed phylactolaemates, $S$. hina does not show longitudinal muscles in the funiculus (see [2]).

5) In all bryozoans, including phylactolaemates, the tentacles are supplied with two longitudinal muscle bands [17]. These are mostly smooth fibres, which is also the case in Stephanella hina. The lophophoral base area where these muscle bands insert differs between phylactolaemates and myolaemates, with a series of small muscular elements being present in the latter. In S. hina, these rootlets are negligible since the frontal muscle bands appear more distally and show no rooting of any sort, and the abfrontal muscles only have a thin elongated proximal extension. This differs from the previous description of the other four families, where the frontal tentacle muscles show one to two different rootlets, which on the oral side are even connected to the pharyngeal musculature. Likewise, the abfrontal muscle bands have a characteristic arrangement not found in $S$. hina, where only a series of a few stacked muscle bundles, intertwined in a zig-zag fashion, are present. Consequently, $S$. hina entirely differs in its basal root structure of the tentacle musculature from the other four analysed families [30, 31].

The epistomial musculature can show two different patterns: muscle fibres embedded in the epithelial linings or individual muscle fibres traversing the epistomial coelom/cavity(see $[17,28,30,31])$, although a mixture of both systems was also detected in the plumatellid Hyalinella punctata [31]. In S. hina, the second state, involving individual fibres, is present and shared by lophopodids and pectinatellids, whereas the three remaining families, Cristatellidae, Fredericellidae and Plumatellidae, share the first configuration. It thus remains difficult to assess which type of epistome musculature is ancestral, but since lophopodids and stephanellids are early branching, it seems reasonable to assume individual traversing fibres as the ancestral condition.

Muscles associated with the proximal border of the lophophoral ring canal were detected in Cristatella mucedo, Pectinatella magnifica and Hyalinella punctata [31] and were probably overlooked in other plumatellids and fredericellids (Schwaha, personal observation). We could not detect any muscles associated with the ring canal, which indicates that these evolved within phylactolaemates or were lost by Stephanella.

6) The retractors show no difference from those of any studied phylactolaemates (see references above). They consist of numerous bundles originating from the body wall and attach at several locations on the oral side of the polypide. They are of a smooth fibre type.

\section{Nervous system}

The general structure of the nervous system is similar to that of other bryozoans $[17,23,25,32]$. The most striking difference is the unique arrangement of the ganglionic horns in Stephanella hina. These proceed distally from the lateral sides of the cerebral ganglion and bend medially to extend towards the lateral margins of the epistome. In other phylactolaemates, the ganglionic horns extend in a straight line distally towards the tip of the lophophoral arms [23, 27, 31, 33], and see Fig. 17). Since $S$. hina is the only representative with such an unusual condition, it is concluded that this characteristic (like the general lophophore situation, see above) is apomorphic. The traverse of the bent ganglionic horns is reminiscent of the epistomial nerve (see [34]), but such a nerve could not be detected in more recent analyses. Instead, the epistome is innervated by a plexus emanating directly from the cerebral ganglion, as also described for Hyalinella punctata [25]:

Additional differences in the nervous system are evident in the detailed tentacle innervation that in Stephanella hina appears to completely lack latero-abfrontal neurite bundles in each tentacle, which are otherwise found in all other phylactolaemates [23, 25] and most other lophophorates [5]. The abfrontal neurite bundle is always formed by the medial fusion of two intertentacular roots. In other phylactolaemates, the lateral roots continue as latero-abfrontal neurite bundles. However, $S$. hina seems to be the first phylactolaemate recently investigated that lacks any sign of these latero-abfrontal neurite bundles. The current data do not support any abfrontal lateral neurite bundles, but to completely verify the presence or absence of these thin neurites, transmission electron microscopy would be necessary.

In addition to the apparent lack of latero-abfrontal neurite bundles, the roots of the medio-frontal bundles mostly emerge directly from the circum-oral nerve ring $(\mathrm{CON})$, with only a few emerging from the radial nerves. 
The latter condition is described for most other phylactolaemates $[23,25]$. Hence, the condition in S. hina is reminiscent of the medio-frontal nerves of myolaemate bryozoans that show a similar origin with mostly two roots emerging intertentacularly from the $\mathrm{CON}[16,17$, $35,36]$.

Concerning the remaining, more peripheral neuronal elements, the plexus innervating the digestive tract and tentacle sheath is more diffuse and does not show more prominent neurite bundles on either the oral or anal side of the polypide, which was reported for all other species $[23,25,32,37]$. Concentrated neurite bundles, as found in most phylactolaemates, are also the usual condition in myolaemates that lack a plexus in these areas. The remaining gut shows as little innervation with staining against acetylated alpha-tubulin as previously reported for Hyalinella punctata [25] and Cristatella mucedo [38]. Distinct intraepithelial, probably sensory, cells, as found in S. hina, were also encountered in the aforementioned species.

\section{Conclusions}

Although Stephanella hina is clearly a phylactolaemate and possesses many morphological characteristics similar if not identical to those of other members of the clade, there are numerous unique characteristics underlining the special position of this little studied species. These are most apparent in the structure of the lophophore, including the arrangement of the forked canals in the inner lophophoral arc and the ganglionic horns. Additional finer details, such as the lack of funicular musculature, latero-abfrontal neurite bundles or smooth caecum musculature, support that $S$. hina is a distinct family among Phylactolaemata (see also [14]). Although often regarded as one of the earliest branches, if not a sister group, to the remaining phylactolaemate families, it remains difficult to assess whether these unique characteristics are plesiomorphic or apomorphic.

\section{Acknowledgements}

Special thanks to the dean's office of the Faculty of Life Sciences, University of Vienna, for financial support to travel to Japan. Thanks to Julia Bauder and Julian Bibermair (University of Vienna) for sectioning some material.

\section{Authors' contributions}

TS designed the study, carried out most laboratory work and drafted the manuscript. MH organized the field studies sampled the material, aided in the interpretation of the data and contributed to the writing of the manuscript. The authors read and approved the final manuscript.

\section{Funding}

This study is supported by FWF grant no. P 32088, granted to TS.

Availability of data and materials

Data are available upon reasonable request.

Ethics approval and consent to participate

Work on bryozoans does not require specific ethics approval.
Consent for publication

Not applicable.

\section{Competing interests}

The authors declare no competing interests.

\section{Author details}

'Department of Evolutionary Biology, University of Vienna, Althanstraße 14, 1090 Vienna, Austria. ${ }^{2}$ Kitasato University, School of Marine Biosciences, Kitasato 1-15-1, Sagamihara-Minami, Kanagawa 252-0373, Japan.

Received: 13 April 2020 Accepted: 31 October 2020

Published online: 10 November 2020

\section{References}

1. Waeschenbach A, Taylor PD, Littlewood DTJ. A molecular phylogeny of bryozoans. Mol Phylogenet Evol. 2012;62:718-35.

2. Schwaha T, Ostrovsky AN, Wanninger A. Key novelties in the evolution of aquatic colonial phylum Bryozoa: evidence from soft body morphology. Biol Rev. 2020.

3. Wood TS: Phyla Ectoprocta and Entoprocta (bryozoans). In Ecology and general biology, Vol I: Thorp and Covich's freshwater invertebrates, 4th ed. Thorp JH, Rogers DC. London: Academic Press; 2014: 327-345.

4. Schwaha T. Phylactolaemata. In: Schwaha T, editor. Handbook of zoology, Bryozoa. Berlin: De Gruyter; 2020.

5. Temereva EN. Morphology evidences the lophophorates monophyly: brief review of studies on the lophophore innervation. Invertebrate Zool. 2017;14: 85-91.

6. Temereva EN. Innervation of the lophophore suggests that the phoronid Phoronis ovalis is a link between phoronids and bryozoans. Sci Rep. 2017;7.

7. Marlétaz F, Peijnenburg KTCA, Goto T, Satoh N, Rokhsar DS. A new Spiralian phylogeny places the enigmatic arrow Worms among Gnathiferans. Curr Biol. 2019;29:312-318.e313.

8. Okuyama M, Wada H, Ishii T. Phylogenetic relationships of freshwater bryozoans (ectoprocta, Phylactolaemata) inferred from mitochondrial ribosomal DNA sequences. Zool Scr. 2006:35:243-9.

9. Hirose M, Dick MH, Mawatari SF. Molecular phylogenetic analysis of phylactolaemate bryozoans based on mitochondrial gene sequences. In: Hageman SJ, MMJ K, Winston JE, editors. Proceedings of the 14th international Bryozoology association conference, Boone, North Carolina, July 1-8, 2007, Virginia Museum of Natural History Special Publication no 15. Martinsville: Virginia Museum of Natural History: 2008. p. 65-74.

10. Toriumi M. Taxonomical study on fresh-water Bryozoa. XI. Stephanella hina Oka. Sci Rep Tohoku Imperial Univ Fourth Series (Biology). 1955;21:131-6.

11. Hirose M. Diversity of freshwater and marine bryozoans in Japan. In: Motokawa M, Kajihara H, editors. Species diversity of animals in Japan. Japan: Springer; 2017. p. 629-49.

12. Oka A. Über eine neue Gattung von Süsswasserbryozoen. Annot Zool Jap. 1908:6:277-85

13. Mukai H. Systematic position of Stephanella hina (Bryozoa: Phylactolaemata), with special reference to the budding site and the attachment of sessoblasts. Zool Sci (Tokyo). 1990;7:947-54.

14. Schwaha T, Hirose M, Wanninger A. The life of the freshwater bryozoan Stephanella hina (Bryozoa, Phylactolaemata) - a crucial key to elucidate bryozoan evolution. Zool Lett. 2016:2:25.

15. Schwaha T, Wood TS, Wanninger A. Myoanatomy and serotonergic nervous system of the ctenostome Hislopia malayensis: evolutionary trends in bodyplan patterning of ectoprocta. Front Zool. 2011;8:11.

16. Schwaha TF, Handschuh S, Ostrovsky AN, Wanninger A. Morphology of the bryozoan Cinctipora elegans (Cyclostomata, Cinctiporidae) with first data on its sexual reproduction and the cyclostome neuro-muscular system. BMC Evol Biol. 2018:18:92

17. Schwaha T. Morphology of bryozoans. In: Schwaha T, editor. Handbook of zoology: Bryozoa. Berlin: DeGruyter; 2020

18. Schwaha T, Wanninger A. Unity in diversity: a survey of muscular systems of ctenostome Gymnolaemata (Lophotrochozoa, Bryozoa). Front Zool. 2018;15: 24.

19. Mukai H, Oda S. Histological and histochemical studies on the epidermal system of higher phylactolaemate bryozoans. Annot Zool Jap. 1980;53:1-17. 
20. Gruhl A. Occurrence and identity of "white spots" in Phylactolaemata. In: Ernst A, Schäfer P, Scholz J, editors. Bryozoan Studies 2010. Verlin Heidelberg: Springer-Verlag; 2013. p. 91-102.

21. Mukai H, Terakado K, Reed CG. Bryozoa. In: Harrison FW, Woollacott RM, editors. Microscopic anatomy of invertebrates. Volume 13. New York: WileyLiss; 1997. p. 45-206.

22. Gruhl A, Wegener I, Bartolomaeus T. Ultrastructure of the body cavities in Phylactolaemata (Bryozoa). J Morphol. 2009;270:306-18.

23. Shunkina KV, Zaytseva OV, Starunov W, Ostrovsky AN. Comparative morphology of the nervous system in three phylactolaemate bryozoans. Front Zool. 2015;12.

24. Schwaha $T$, Handschuh $S$, Redl E, Wanninger A. Insights into the organization of plumatellid 'larvae' (Lophotrochozoa, Bryozoa) by means of 3D imaging and confocal microscopy. J Morphol. 2015;276:109-20.

25. Ambros M, Wanninger A, Schwaha T. Neuroanatomy of the plumatellid bryozoan Hyalinella punctata reveals a common pattern in a small group of freshwater bryozoans. J Morphol. 2018;279:242-58.

26. Gruhl A, Bartolomaeus T. Ganglion ultrastructure in phylactolaemate Bryozoa: evidence for a neuroepithelium. J Morphol. 2008;269:594-603.

27. Schwaha T, Handschuh S, Redl E, Walzl M. Organogenesis in the budding process of the freshwater bryozoan Cristatella mucedo Cuvier 1789 (Bryozoa, Phylactolaemata). J Morphol. 2011;272:320-41.

28. Schwaha T. Morphology and ontogeny of Lophopus crystallinus lophophore support the epistome as ancestral character of phylactolaemate bryozoans. Zoomorphology. 2018;137:355-66.

29. Silen L. On the division and movements of the alimentary canal of the Bryozoa. Ark Zool. 1944;35A:1-41.

30. Schwaha T, Wanninger A. Myoanatomy and serotonergic nervous system of plumatellid and fredericellid phylactolaemata (lophotrochozoa, ectoprocta). J Morphol. 2012;273:57-67.

31. Gawin N, Wanninger A, Schwaha T. Reconstructing the muscular ground pattern of phylactolaemate bryozoans: first data from gelatinous representatives. BMC Evol Biol. 2017;17:225.

32. Gruhl A, Schwaha T: Bryozoa. In Structure and evolution of invertebrate nervous system. Schmidt-Rhaesa A, Harzsch S, Purschke G. Oxford: Oxford University Press; 2015: 325-340.

33. Cori CJ. Ordnung der Tentaculata: Bryozoa. In: Kükenthal W, Krumbach T, editors. Handbuch der Zoologie. Volume 3 (2). Berlin: Walter de Gruyter \& Co; 1941. p. 263-502

34. Gerwerzhagen A. Beiträge zur Kenntnis der Bryozoen, I. das Nervensystem von Cristatella mucedo. Z Wiss Zool. 1913;107:309-45.

35. Pröts $P$, Wanninger A, Schwaha T. Life in a tube: morphology of the ctenostome bryozoan Hypophorella expansa. Zool Lett. 2019;5:28.

36. Worsaae K, Frykman T, Nielsen C. The neuromuscular system of the cyclostome bryozoan Crisia eburnea (Linnaeus, 1758). Acta Zool. 2020;101: $133-46$

37. Lutaud G. The bryozoan nervous system. In: Woollacott RM, Zimmer RL, editors. Biology of bryozoans. New York: Academic press; 1977. p. 377-410

38. Schwaha T. Bryozoa, Cristatella mucedo: Nervous system. Microscopic anatomy of animals 2020. https://doi.org/10.1002/9781118158036. maa000006.

\section{Publisher's Note}

Springer Nature remains neutral with regard to jurisdictional claims in published maps and institutional affiliations.

Ready to submit your research? Choose BMC and benefit from:

- fast, convenient online submission

- thorough peer review by experienced researchers in your field

- rapid publication on acceptance

- support for research data, including large and complex data types

- gold Open Access which fosters wider collaboration and increased citations

- maximum visibility for your research: over $100 \mathrm{M}$ website views per year

At BMC, research is always in progress.

Learn more biomedcentral.com/submissions 